\title{
EFFECTS OF EDGE-STIFFENED CIRCULAR HOLES ON THE WEB CRIPPLING STRENGTH OF COLD-FORMED STEEL CHANNEL SECTIONS UNDER ONE-FLANGE LOADING
}

\section{CONDITIONS}

\author{
Asraf Uzzaman ${ }^{\mathrm{a}}$, James B.P Lim ${ }^{\mathrm{b}}$, David Nash ${ }^{\mathrm{a}}$, Ben Young \\ a Department of Mechanical and Aerospace Engineering, The University of Strathclyde, 75 Montrose Street, Glasgow G1 1XJ \\ b Department of Civil and Environmental Engineering, University of Auckland, New Zealand \\ c Department of Civil Engineering, The University of Hong Kong, Pokfulam Road, Hong Kong
}

\begin{abstract}
Cold-formed steel sections are often used as wall studs or floor joists and such sections often include web holes for ease of installation of services. The holes are normally punched or bored and are unstiffened; when the holes are near to points of concentrated load, web crippling can be the critical design consideration. Recently, a new generation of cold-formed steel channel sections with edge-stiffened circular holes has been developed, for which web crippling may not be so critical. In this paper, a combination of experimental investigation and non-linear elasto-plastic finite element analyses are used to investigate the effect of such edge-stiffened holes under the interior-one-flange (IOF) and end-one-flange (EOF) loading conditions; for comparison, sections without holes and with unstiffened holes are also considered. A total of 90 results comprising 36 tests and 54 finite element analysis results are presented. Owing to manufacturing constraints, in the test programme, the edge-stiffener length was fixed at $13 \mathrm{~mm}$. Good agreement between the experimental and finite element results was obtained. For the case of the unstiffened hole, it is shown that the web crippling strength is reduced by up to $12 \%$ and $28 \%$ for the IOF and EOF loading conditions, respectively. However, with the edge-stiffened circular hole, the web crippling strength is only reduced by $3 \%$ for the IOF loading condition and there is no reduction in strength for
\end{abstract}


the EOF loading condition. The finite element model was used for the purposes of a parametric study on the effects of different hole sizes, edge-stiffener length and distances of the web holes to the near edge of the bearing plate. The results indicate that with a suitable edge-stiffener length, the web crippling strength of cold-formed steel channel section with holes can be as high as the one without holes.

\title{
Keywords
}

Cold-formed steel; Web crippling; Channel section; Circular web hole; Edge-stiffened web hole ; Finite element analysis

\author{
Nomenclature \\ A Web holes ratio; \\ a Diameter of circular web holes; \\ $b_{f} \quad$ Overall flange width of section; \\ $b_{l} \quad$ Overall lip width of section; \\ COV Coefficient of variation; \\ $D \quad$ Overall web depth of section; \\ E Young's modulus of elasticity; \\ FEA Finite element analysis; \\ $h \quad$ Depth of the flat portion of web; \\ $L \quad$ Length of the specimen; \\ $N \quad$ Length of the bearing plate; \\ $P \quad$ Experimental and finite element ultimate web crippling load per web; \\ $P_{\text {EXP }} \quad$ Experimental ultimate web crippling load per web; \\ $P_{\text {FEA }} \quad$ Web crippling strength per web predicted from finite element (FEA);
}




\begin{tabular}{|ll|}
\hline$r_{\mathrm{q}}$ & Inside corner radius between web and hole edge-stiffener; \\
$r_{\mathrm{i}}$ & Inside corner radius of section; \\
$t$ & Thickness of section; \\
$q$ & Length of web holes edge-stiffener; \\
$Q$ & Web holes edge-stiffener length ratio; \\
$x$ & Worizontal clear distance of the web holes to the near edge of the bearing plate; \\
$\mathrm{X}$ & Static $0.2 \%$ proof stress; and \\
$\sigma_{0.2}$ & Static ultimate tensile strength. \\
$\sigma_{u}$ & \\
\hline
\end{tabular}




\section{Introduction}

Cold-formed steel sections are increasingly used in residential and commercial construction for both primary and secondary framing members. Such thin-walled sections are well-known to be susceptible to web crippling, particularly at points of concentrated load or reaction [1] (see Fig.1). Furthermore, openings in the web are often used to allow ease of installation of electrical or plumbing services. Such openings, however, result in the sections being more susceptible to web crippling, particularly when concentrated loads are applied near to the openings.

Web holes in cold-formed steel sections are normally punched or bored and so are unstiffened (see Fig.2(a)). Recently, Yu [2] described a study on a new generation of cold-formed steel channel sections having web holes that are edge-stiffened. Fig.2(b) shows a photograph of a cold-formed steel channel section with an edge-stiffened circular holes [3]. As can be seen, the web holes are stiffened through a continuous edge stiffener/lip around the perimeter of the hole. The study by Yu [2], while limited to bending, indicates that edge-stiffened holes can significantly improve the strength of cold-formed steel channel sections.

This paper is concerned with the web crippling strength of cold-formed steel channel sections having edge-stiffened circular web holes. Fig.3 shows the definition of symbols used in this paper. While no previous research has considered the web crippling strength of cold-formed steel channel sections with edge-stiffened circular web holes, previous work on web crippling has been reported by Uzzaman et al. [4-7] and Lian et al. [8-11], who proposed design recommendations in the form of web crippling strength reduction factor equations for channel-sections under the interior-oneflange (IOF) and end-one-flange (EOF) loading conditions. Yu and Davis [12], Sivakumaran and Zielonka [13], LaBoube et al. [14-15] and Chung [16-17] also 
reported research on the web crippling of channel section with unstiffened web openings. For aluminium sections, Zhou and Young [18] conducted a series of tests and numerical investigation on web crippling square hollow sections, again with unstiffened web holes. Yousefi et al. [19-22] proposed unified strength reduction factor equations for the web crippling strength of cold-formed stainless steel lipped channel-sections with circular web openings.

In this paper, a combination of experimental investigation and non-linear elastoplastic finite element analyses (FEA) are used to investigate the effect of edge-stiffened circular web holes on the web crippling strength of lipped channel sections for the interior-one-flange (IOF) and end-one-flange (EOF) loading conditions, as shown in Fig.4 and Fig.5, respectively.

The general purpose finite element program ABAQUS [23] was used for the numerical investigation. A good agreement between the experimental and finite element results was obtained. The finite element model was then used for the purposes of a parametric study of the effect of different web hole sizes, edge-stiffener length and position of holes in the web. The results indicate that the edge-stiffened circular holes can significantly improve the web crippling strength of cold-formed channel sections.

\section{Experimental investigation}

\subsection{Test specimens}

A test programme was conducted on lipped channel sections, as shown in Fig.3 subjected to web crippling under EOF and IOF loading condition. Two depths of channel-sections were considered, namely the C240 and C290 channels having the nominal depth of $240 \mathrm{~mm}$ and $290 \mathrm{~mm}$, respectively. All holes had a nominal diameter (a) of $140 \mathrm{~mm}$ and an edge-stiffener length $(q)$ of $13 \mathrm{~mm}$; the radius $\left(r_{q}\right)$ between the web and edge-stiffener was $3 \mathrm{~mm}$. The test specimens comprised two different section 
sizes, having nominal thicknesses $(t)$ ranging from $2.0 \mathrm{~mm}$ to $2.5 \mathrm{~mm}$; the nominal depth $(d)$ of the webs ranged from $240 \mathrm{~mm}$ to $290 \mathrm{~mm}$; the nominal flange width $\left(b_{f}\right)$ for both sizes is $45 \mathrm{~mm}$.

The test programme considered both webs having unstiffened circular holes and webs having edge-stiffened circular holes. Channel sections with no circular web holes (i.e. plain webs) were also tested, in order that the strength reduction can be determined experimentally.

The ratio of the diameter of the circular holes to the depth of the flat portion of the webs $(a / h)$ were 0.6 and 0.5 for the $\mathrm{C} 240$ and C290 section, respectively. All test specimens were fabricated with the circular web holes located at the mid-depth of the webs and centred above the bearing plates, with a horizontal clear distance to the near edge of the bearing plates $(x)$, as shown in Fig.6 (a) and Fig.7 (a).

The specimen lengths $(L)$ used were according to the North American Specification [24] and the AISI Specification [25]. Generally, the distance between bearing plates was set to be 1.5 times the overall depth of the web $(d)$ rather than 1.5 times the depth of the flat portion of the web $(h)$, the latter being the minimum specified in the specification. The bearing plates were fabricated using with high strength steel having a thickness of $25 \mathrm{~mm}$. Three lengths of bearing plates $(N)$ were used: $50 \mathrm{~mm}, 75$ $\mathrm{mm}$ and $100 \mathrm{~mm}$.

\subsection{Specimens labelling}

Table 1 and Table 2 show the measured test specimen dimensions for IOF and EOF conditions, respectively, using the nomenclature defined in Fig.3. In Table 1 and Table 2, the specimens were labelled such that the loading condition, the nominal dimension of the specimen and the length of the bearing as well as the ratio of the diameter of the holes to the depth of the flat portion of the webs $(a / h)$ could be 
identified from the label. For example, the labels "IOF 240x45x15-N50-NH" and "EOF 240x45x15-N50-NH define the following specimens:

- $\quad$ The first three letters indicate the web crippling loading condition used i.e. Interior-One-Flange (IOF) or End-One-Flange (EOF)

- The symbols $d \times b_{\mathrm{f}} \times b_{1}$ refer to the nominal dimensions of the specimens in millimetres i.e. $240 \times 45 \times 15$ means $d=240 \mathrm{~mm} ; b_{\mathrm{f}}=45 \mathrm{~mm}$; and $b_{1}=13 \mathrm{~mm}$

- $\quad$ The notation "N50" indicates the length of bearing in millimetres (i.e. $N=50$ $\mathrm{mm})$

- $\quad$ The last three notations "NH", "USH" and "ESH" indicates the web holes cases. "NH" represents the no web hole case, "USH" represents a web having a hole that is unstiffened, and "ESH" represents a web having a hole that is edge-stiffened.

\subsection{Material properties}

Six coupon tests were carried out to determine the material properties of the channel specimens. The tensile coupons were taken from the centre of the web plate in the longitudinal direction of the untested specimens. The tensile coupons were prepared and tested according to the British Standard for Testing and Materials [26] for the tensile testing of metals using $12.5 \mathrm{~mm}$ wide coupons of a gauge length $50 \mathrm{~mm}$. The coupons were tested in a MTS displacement controlled testing machine using friction grips. Two strain gauges and a calibrated extensometer of $50 \mathrm{~mm}$ gauge length were used to measure the longitudinal strain. The material properties obtained from the tensile coupon tests are summarised in 
Table 3, which includes the measured static $0.2 \%$ proof stress $\left(\sigma_{0.2}\right)$ and the static tensile strength $\left(\sigma_{u}\right)$.

\subsection{Test rig and procedure}

The specimens were tested under the IOF and EOF loading conditions specified in the North American Specification [24] and the AISI Specification [25] as shown in Fig.6 and Fig.7. For the IOF loading conditions, two channel sections were used to provide symmetric loading. The specimens were bolted to support blocks at each end of the specimens. A bearing plate was positioned at the mid-length of the specimens. The load was applied through bearing plate. Hinge supports were simulated by two half rounds in the line of action of the force. Two displacement transducers (LVDTs) were positioned at the two edges of bearing plate to measure the vertical displacements. For the EOF loading conditions, two channel specimens were used to provide symmetric loading. The specimens were bolted to a load transfer block at the central loading point. The load was applied through the load transfer plate bolted to the channel sections. Two identical bearing plates of the same width were positioned at both ends of the specimen. Hinge supports were simulated by two half rounds in the line of action of the force. Four displacement transducers (LVDTs) were used to measure the vertical displacements.

A servo-controlled Tinius-Olsen testing machine was used to apply a concentrated compressive force to the test specimens. Displacement control was used to drive the hydraulic actuator at a constant speed of $0.05 \mathrm{~mm} / \mathrm{min}$ for all the test specimens. The bearing plates were fabricated using a high strength steel. All the bearing plates were machined to specified dimensions, and the thickness was $25 \mathrm{~mm}$. In the experimental investigation, three different lengths of bearing plates $(N)$ were used, namely, $50 \mathrm{~mm}$, 
$75 \mathrm{~mm}$ and $100 \mathrm{~mm}$. The flanges of the channel section specimens were unfastened the bearing plates during testing.

\subsection{Test results}

A total of 36 specimens were tested under IOF and EOF loading conditions. The experimental ultimate web crippling loads per web $\left(P_{\text {EXP }}\right)$ for IOF and EOF loading conditions are given in Table 1 and Table 2, respectively. The typical failure mode of web crippling of the specimens is shown in Fig.9 (a) and Fig.10 (a).

The web crippling strengths for sections with web holes divided by the sections without web holes, which is the strength reduction percentage $(R)$, was used to quantify the degrading influence of the web holes on the web crippling strengths.

As shown in Table 1, for the IOF loading condition, it is shown that the web crippling strength reduced $12.54 \%$ for the specimen IOF290x45 $\times 15-\mathrm{N} 100-\mathrm{USH}$ and $2.83 \%$ for the specimen IOF290x45 15 -N100-ESH. As shown in Table 2, for the EOF loading condition, it is shown that the web crippling strength reduced $28.26 \%$ for the specimen EOF240x45x15-N100-USH and $1.45 \%$ for the specimen EOF240x45x15N50-ESH.

\section{Numerical Investigation}

\subsection{General}

The non-linear elasto-plastic general purpose finite element program ABAQUS [23] was used to simulate the channel sections with and without holes subjected to web crippling. The bearing plates, the channel section with circular holes and the interfaces between the bearing plates and the channel section have been modelled. In the finite element model, the measured cross-section dimensions and the material properties obtained from the tests were used. The model was based on the centreline dimensions of the cross-sections. Specific modelling issues are described in the following subsection. 


\subsection{Geometry and material properties}

Due to symmetry, only half of the test setup was modelled, as shown in Fig.9 (b) and Fig.10 (b). The dimensions of the channel section modelled are given in Table 1 and Table 2. Contact pairs are defined between the bearing plate and the cold-formed steel section. In addition, for the IOF loading condition, contact pairs are defined between the support block and cold-formed steel section. For the EOF loading condition, contact pair are defined between the load transfer block and cold-formed steel section.

The value of Young's modulus was $205 \mathrm{kN} / \mathrm{mm}^{2}$ and Poisson's ratio was 0.3 . ABAQUS required the material stress-strain curve input as true stress-true plastic strain. The stress-strain curves were directly obtained from the tensile tests and converted into true stress- true plastic strain curves using Equation 1 and Equation 2, as specified in the ABAQUS manual [23],

$$
\begin{aligned}
& \sigma_{\text {true }}=\sigma(1+\varepsilon) \\
& \varepsilon_{\text {true }(p l)}=\ln (1+\varepsilon)-\frac{\sigma_{\text {true }}}{E}
\end{aligned}
$$

where $E$ is the Young's Modulus, $\sigma$ and $\varepsilon$ are the engineering stress and strain, respectively in ABAQUS [23].

\subsection{Element type and mesh sensitivity}

Fig.9 (b) and Fig.10 (b) show details of a typical finite element mesh of the channel section, the bearing plate, load transfer block and support block. A mesh sensitivity analysis was used to investigate the effect of different element sizes in the cross-section of the channel sections. Finite element mesh sizes were $5 \mathrm{~mm} \times 5 \mathrm{~mm}$ for the cold-formed steel channel sections and $8 \mathrm{~mm} \times 8 \mathrm{~mm}$ for the bearing plates and load transfer block. 
It is necessary to finely mesh the corners of the section due to the transfer of stress from the flange to the web. From the mesh sensitivity analysis, due to the contact between the bearing plate and inside round corners that form the bend between the flange and web, it was found that at least fifteen elements were required for the corners between the flange and web. On the other hand, for the corners between the flange and lip of the section, only three elements were required.

Cold-formed steel channel sections with and without web holes were modelled using S4R shell element. The S4R is a four-node double curved thin or thick shell element with reduced integration and finite membrane strains. It is mentioned in the ABAQUS Manual [23] that the S4R element is suitable for complex buckling behaviour. The S4R has six degrees of freedom per node and provides accurate solutions to most applications. The bearing plates and load transfer block were modelled using analytical rigid plates and C3D8R element, which is suitable for threedimensional modelling of structures with plasticity, stress stiffening, large deflection, and large strain capabilities. The solid element is defined by eight nodes having three translational degrees of freedom at each node.

\subsection{Loading and boundary conditions}

The vertical load applied to the channel section through the bearing plate for the IOF and load transfer block for the EOF in the laboratory tests was modelled using displacement control. In the finite element model, a displacement in the vertical $y$ direction was applied to the reference point of the analytical rigid plate that modelled the bearing plate and load transfer block. The nodes on symmetry surface of load transfer block, support blocks and bearing plates were prevented from translational axes in the $x$ direction and rotation about the $y$ and $z$ axes. The channel section specimens were tested in pairs, which were bolted to load transfer block for the EOF and support blocks for the IOF through the web by a vertical row of M16 high tensile bolts. 
In the shell element idealisation, cartesian connectors were used to simulate the bolts instead of physically modelling bolts and holes. "CONN3D2" connector elements were used to model the in-plane translational stiffness i.e. $y$ - and $z$-directions. The stiffness of the connectors element was $10 \mathrm{kN} / \mathrm{mm}$, which Lim and Nethercot [27,28] suggest would be suitable. In the $\mathrm{x}$ direction, the nodes were prevented from translating.

Contact between the bearing plate and the cold-formed steel section was modelled in ABAQUS using the contact pairs option. Contac pair (surface-to-surface) was used to model the interface between the rigid plate (master surface) and the flange of the crosssection (slave surface, extended up to the corners) assuming frictionless response in the tangential direction and hard response in the normal one. For the IOF loading condition, contact pairs were modelled between the support block, bearing plate and cold-formed steel section. For the EOF loading condition, contact pairs were modelled between the load transfer block, bearing plates and cold-formed steel section. All contact surfaces were not allowed to penetrate each other. No friction was modelled between the surfaces.

\subsection{Verification of finite element model}

In order to validate the finite element model, the experimental failure loads were compared against the failure load predicted by the finite element analysis. The main objective of this comparison was to verify and check the accuracy of the finite element model. A comparison of the test results $\left(P_{\mathrm{EXP}}\right)$ with the numerical results $\left(P_{\mathrm{FEA}}\right)$ of web crippling strengths per web is shown in Table 4 and Table 5 for the IOF and EOF condition, respectively. It can be seen that good agreement has been achieved between both results for all specimens. The mean value of the $P_{\mathrm{EXP}} / P_{\mathrm{FEA}}$ ratio is 0.99 and 0.98 with the corresponding coefficient of variation (COV) of 0.02 and 0.01 for the IOF and EOF loading condition, respectively. A maximum difference of $4 \%$ and $5 \%$ was observed between the experimental and the numerical results for the specimen 
IOF290x45x15-N100-USH and EOF240x45x15-N50-USH, respectively. The web deformation curves predicted by finite element analysis were compared with the experimental curves, as shown in Fig.8 for the IOF and EOF loading conditions.

The web crippling failure mode observed from the tests has been also verified by the finite element model for the IOF and EOF loading conditions, as shown in Fig.9 and Fig.10, respectively. It is shown that good agreement is achieved between the experimental and finite element results for both the web crippling strength and the failure mode. Fig.11 shows the variation of web crippling strength due to with and without web holes against the three different bearing plate lengths. A parametric study is performed in the following section to obtained optimized dimensions of the web holes profiles for the cold-formed steel sections.

\section{Parametric Study}

The finite element model developed closely predicted the web crippling behaviour of the channel sections with circular web holes under IOF and EOF loading conditions. Using this validated model, parametric studies were carried out to study the effects of web holes sizes, location of the holes and length of the edge-stiffener on the web crippling strengths of channel sections subjected to web crippling.

The web crippling strength predicted was influenced primarily by the ratio of the hole depth to the flat portion of the web, $a / h$, the location of the hole as defined by the distance of the hole from the edge of the bearing divided by the flat portion of the web, $x / h$ and the ratio of the edge-stiffener length to the flat portion of the web, $q / h$. In order to find the effect of $a / h, x / h$ and $q / h$ on web crippling strength considering web holes, three separate parametric studies were carried.

In this study section C240 was used, having a nominal depth and thickness of 240 $\mathrm{mm}$ and $1.85 \mathrm{~mm}$, respectively. A length of bearing plate of $50 \mathrm{~mm}$ was considered. 
The specimens were labelled according to the analysis type. For example the label 'EOF240-N50-X0.2-A0.4' stands for the loading condition, bearing plate length, web holes distance ratio (X0.2 means $x / h=0.2$ ) and web holes ratio (A0.4 means $a / h=0.4$ ). As can been seen on Table 6 and Table 7, Q0.04 stands for the web holes edge-stiffener length ratio $q / h=0.04$.

The ratios of the diameter of the holes $(a)$ to the depth of the flat portion of the webs $(h)$ were $0.4,0.6$ and 0.8 . The ratio $x / h$ (the distance of the web holes to the depth of the flat portion of the webs) were $0.2,0.4$ and 0.6 . The ratio $q / h$ of the length of stiffener to the depth of the flat portion of the webs were $0.04,0.06$ and 0.08 .

A total of 60 specimens was analysed in the parametric study investigating the effects of the ratio $a / h, x / h$ and $q / h$. The web crippling strength of the sections without the web holes were obtained. The cross-section dimensions as well as the web crippling strengths $\left(P_{\mathrm{FEA}}\right)$ per web predicted from the FEA are summarised in Table 6 and Table 7 for the IOF and EOF loading conditions, respectively.

\section{Effect of $a / h, x / h$, and $q / h$ on web crippling strength}

Evaluation of the finite element results shows that the ratios $a / h, x / h$ and $q / h$ are the primary parameters influencing the web crippling behaviour of the sections with web holes. For the IOF and EOF loading conditions, the effect of the ratios of $a / h, x / h$ and $q / h$ on web crippling strength of the channel sections without web holes, with unstiffened circular web holes and with edge-stiffened circular web holes are shown in Fig.12, Fig.13 and Fig.14.

As can be seen from Fig.12, as the web hole diameter ratio a/ $h$ increases from 0.4 to 0.8 , the web crippling strength decreases against different web holes locations and length of the edge-stiffeners for both loading conditions. Fig.13(a) shows the effect of web holes distance ratio $x / h$ web crippling strength for the IOF loading condition. With 
the respect of web holes diameter ratio A0.6, the results show the increase of web crippling strength when web holes distance ratio $\mathrm{x} / h$ increases from 0.2 to 0.6 . For smaller web hole diameter ratio A0.4, web crippling strength decrease when web holes distance ratio $x / h$ increases from 0.2 to 0.6 . For the bigger hole diameter ratio A0.8, web crippling strength decrease but eventually it increases when web holes distance ratio $x / h$ increases 0.4 to 0.6 .

Fig.13(b) shows the effect of web holes distance ratio $x / h$ web crippling strength for the EOF loading condition. With the respect of web holes diameter ratio A0.4 and A0.6, the results show the decrease of web crippling strength when web holes distance ratio $x / h$ increases from 0.2 to 0.6 . For the bigger hole diameter ratio A0.8, web crippling strength decrease but eventually it increases when web holes distance ratio $x / h$ increases 0.4 to 0.6 .

It is seen from Fig.14 the parameter $q / h$ noticeably affects the web crippling strength. Web crippling strengths are improved when the sections have edge-stiffened circular holes in the web and the increasingly grows as the hole diameter becomes larger for the IOF and EOF loading conditions.

In order to restore original the web crippling strength for the IOF loading condition for a section having a web hole ratio $a / h$ of 0.6 with holes distance ratio $x / h$ of 0.2 , it can be recommended that the holes edge-stiffener length ratio $q / h$ be at least 0.04 . Similarly, for the EOF loading condition, it can be recommended that the holes edgestiffener length ratio $q / h$ be at least 0.06 .

\section{Conclusions}

The experimental and the numerical investigations of lipped channel sections with circular unstiffened and edge-stiffened circular web holes subjected to web crippling have been presented. Web holes located at the mid-depth of the web with a 
horizontal clear distance to the near edge of bearing plate were considered. A series of tests was conducted on lipped channel sections with web holes subjected to the interiorone-flange (IOF) and end-one-flange (EOF) loading conditions. A total of 36 specimens were tested under IOF and EOF loading conditions. The channel specimens had the measured $0.2 \%$ proof stresses (yield stresses) of $268 \mathrm{MPa}$ and $328 \mathrm{MPa}$ for the two different section sizes.

For the unstiffened hole, it has been shown that for case of specimen IOF$290 \times 45 \times 15-N 100$, the web crippling strength was reduced by $12 \%$ for the IOF loading condition. Similarly, for the case of specimen EOF-240x45x15-N100, the web crippling strength was reduced by $28 \%$ for the EOF loading condition. However, with the edgestiffened circular hole, the web crippling strength was only reduced by $3 \%$ for the IOF loading condition and there was no reduction in strength for the EOF loading condition.

A finite element model that incorporated the geometric and the material nonlinearities has been developed and verified against the experimental results. The finite element model was shown to be able to closely predict the web crippling behaviour of the channel sections, both with and without web holes. Thereafter, a parametric study was carried out to study the effects of web holes sizes, location of the holes and length of the edge-stiffener on the web crippling strengths of the channel sections. It is shown that the ratios $a / h, x / h$ and $q / h$ are the primary parametric relationships influencing the web crippling behaviour of the sections with the web holes.

Based on the finite element results a correlation was established for the web crippling strength of the channel sections without web holes, with unstiffened and edge-stiffened circular web holes corresponding with the ration $a / h, x / h$ and $q / h$ for the IOF and EOF loading conditions, respectively. The results show that the edge-stiffened 
circular holes can significantly improve the web crippling strength of cold-formed steel channel sections.

\section{Acknowledgements}

The Authors would like to acknowledge Howick Ltd. for providing the test specimens. The experimental work was carried out by Wei Lin and Cong Li, as part of their undergraduate research projects. The authors also wish to thank Ross Reichardt and Mark Byrami for their assistance in preparing the specimens and carrying out the experimental testing. 


\section{References}

[1] Rhodes J, Nash D. An investigation of web crushing behaviour in thin-walled beams. Thin-Walled Structures. 1998;32:207-30.

[2] Yu C. Cold-formed steel flexural member with edge stiffened holes: Behavior, optimization, and design. Journal of Constructional Steel Research. 2012;71:210-8.

[3] Howick. Floor Joist System. Auckland, New Zealand2013.

[4] Uzzaman A, Lim JBP, Nash D, Rhodes J, Young B. Web crippling behaviour of cold-formed steel channel sections with offset web holes subjected to interior-twoflange loading. Thin-Walled Structures. 2012;50:76-86.

[5] Uzzaman A, Lim JBP, Nash D, Rhodes J, Young B. Cold-formed steel sections with web openings subjected to web crippling under two-flange loading conditions - Part I: Tests and finite element analysis. Thin-Walled Structures. 2012;56:38-48.

[6] Uzzaman A, Lim JBP, Nash D, Rhodes J, Young B. Cold-formed steel sections with web openings subjected to web crippling under two-flange loading conditions - Part II: Parametric study and proposed design equations. Thin-Walled Structures. 2012;56:7987.

[7] Uzzaman A, Lim JBP, Nash D, Rhodes J, Young B. Effect of offset web holes on web crippling strength of cold-formed steel channel sections under end-two-flange loading condition. Thin-Walled Structures. 2013;65:34-48. 
[8] Lian Y, Uzzaman A, Lim JBP, Abdelal G, Nash D, Young B. Effect of web holes on web crippling strength of cold-formed steel channel sections under end-one-flange loading condition - Part I: Tests and finite element analysis. Thin-Walled Structures. 2016;107:443-452.

[9] Lian Y, Uzzaman A, Lim JBP, Abdelal G, Nash D, Young B. Effect of web holes on web crippling strength of cold-formed steel channel sections under end-one-flange loading condition - Part II: Parametric study and proposed design equations. ThinWalled Structures. 2016;107:489-501.

[10] Lian Y, Uzzaman A, Lim JBP, Abdelal G, Nash D, Young B. Web Crippling Behaviour of Cold-Formed Steel Channel Sections with Web Holes Subjected to Interior-One-Flange Loading Condition-Part I: Experimental and Numerical Investigation. Thin-Walled Structures, 2017;111:103-112.

[11] Lian Y, Uzzaman A, Lim JBP, Abdelal G, Nash D, Young B. Web Crippling Behaviour of Cold-Formed Steel Channel Sections with Web Holes Subjected to Interior-One-Flange Loading Condition - Part II: Parametric Study and Proposed Design Equations. Thin-Walled Structures, 2017;114:92-106. 
[12] Yu WW, Davis CS. Cold-formed steel members with perforated elements. Journal of the Structural Division. 1973;99:2061-77.

[13] Sivakumaran KS, Zielonka KM. Web crippling strength of thin-walled steel members with web opening. Thin-Walled Structures. 1989;8:295-319.

[14] LaBoube RA, Yu WW, Deshmukh SU, Uphoff CA. Crippling Capacity of Web Elements with Openings. Journal of Structural Engineering. 1999;125:137-41.

[15] LaBoube RA, Yu WW, Langan JE. Cold-formed steel web with openings: Summary report. Thin-Walled Structures. 1997;vol. 28:pp. 355-72.

[16] Chung KF. Structural perfomance of cold formed sections with single and multiple web openings. Part-1: Experimental investigation. The Structural Engineer. 1995;Vol 73.

[17] Chung KF. Structural perfomance of cold formed sections with single and multiple web openings. Part-2: Design rules. The Structural Engineer. 1995;Vol 73.

[18] Zhou F, Young B. Web crippling of aluminium tubes with perforated webs. Engineering Structures. 2010;32:1397-410. 
[19] Yousefi A, Lim JBP, Uzzaman A, Lian Y, Clifton C, Young B. Web crippling strength of cold-formed stainless steel lipped channel-sections with web openings subjected to Interior-One-Flange loading condition. Steel and composite structures. 2016;21:629-659.

[20] Yousefi A, Lim JBP, Uzzaman A, Lian Y, Clifton C, Young B. Design of coldformed stainless steel lipped channel-sections with web openings subjected to web crippling under End-One-Flange loading condition. Advances in Structural Engineering. 2016

[21] Yousefi A, Uzzaman A, Lim JBP, Clifton C, Young B. Numerical investigation of web crippling strength in cold-formed stainless steel lipped channels with web openings subjected to interior-two-flange loading condition. Steel and composite structures. 2017. (In press)

[22] Yousefi A, Uzzaman A, Lim JBP, Clifton C, Young B. Web crippling strength of cold-formed stainless steel lipped channels with web perforations under end-two-flange loading. Advances in Structural Engineering. 2017. (In press)

[23] ABAQUS. Version 6.14. RI, USA:. SIMULIA, Providence; 2014.

[24] NAS. North American Specification for the design of cold-formed steel structural members. Washington, D.C.: American Iron and Steel Institute; 2001.

[25] AISI. Specification for the design of cold-formed steel structural members. Washington, D.C: American Iron and Steel Institute; 2005. 
[26] EN B. 10002-1: 2001. Tensile testing of metallic materials. Method of test at ambient temperature. British Standards Institution2001.

[27] Lim JBP, Nethercot D. Finite Element Idealization of a Cold-Formed Steel Portal Frame. Journal of Structural Engineering. 2003;130:78-94.

[28] Lim JBP, Nethercot DA. Stiffness prediction for bolted moment-connections between cold-formed steel members. Journal of Constructional Steel Research. 2004;60:85-107. 
Table 1 Measured specimen dimensions and experimental ultimate loads for interior-one-flange loading condition (IOF)

\begin{tabular}{|c|c|c|c|c|c|c|c|c|c|c|}
\hline Specimen & $\begin{array}{c}\text { Web } \\
d \\
(\mathrm{~mm})\end{array}$ & $\begin{array}{c}b_{f} \\
(\mathrm{~mm})\end{array}$ & $\begin{array}{c}\text { Lip } \\
b_{l} \\
(\mathrm{~mm})\end{array}$ & $\begin{array}{c}L \\
(\mathrm{~mm})\end{array}$ & $\begin{array}{c}t \\
(\mathrm{~mm})\end{array}$ & $\begin{array}{c}r_{i} \\
(\mathrm{~mm})\end{array}$ & Hole diameter & Bearing length & $\begin{array}{c}\text { Exp.load } \\
\text { (Per web ) } \\
P_{E X P} \\
(\mathrm{kN})\end{array}$ & $\begin{array}{l}\text { Percentage of strength } \\
\text { reduction due to web holes } \\
R \\
(\%)\end{array}$ \\
\hline \multicolumn{11}{|l|}{ Plain section } \\
\hline IOF 240x45x15-N50-NH & 236.33 & 45.08 & 18.57 & 970.0 & 1.98 & 3 & - & 50 & 16.07 & - \\
\hline IOF $240 \times 45 \times 15-\mathrm{N} 75-\mathrm{NH}$ & 238.17 & 44.77 & 17.62 & 994.7 & 1.97 & 3 & - & 75 & 17.3 & - \\
\hline IOF 240x45x15-N100-NH & 237.56 & 44.77 & 17.59 & 1020.0 & 1.97 & 3 & - & 100 & 18.5 & - \\
\hline IOF 290x45x15-N50-NH & 289.33 & 45.38 & 18.56 & 1120.1 & 2.48 & 3 & - & 50 & 30.68 & - \\
\hline IOF $290 \times 45 \times 15-\mathrm{N} 75-\mathrm{NH}$ & 289.67 & 45.17 & 18.57 & 1144.6 & 2.48 & 3 & - & 75 & 32.97 & - \\
\hline IOF 290x45x15-N100-NH & 288.21 & 44.75 & 19.47 & 1170.2 & 2.46 & 3 & - & 100 & 34.6 & - \\
\hline \multicolumn{11}{|l|}{ Unstiffened hole } \\
\hline IOF 240x45x15-N50-USH & 235.12 & 44.76 & 17.45 & 969.0 & 1.97 & 3 & 140 & 50 & 15.72 & -2.18 \\
\hline IOF 240x45x15-N75-USH & 236.54 & 45.15 & 17.76 & 994.3 & 1.98 & 3 & 140 & 75 & 16.64 & -3.82 \\
\hline IOF 240x45x15-N100-USH & 235.54 & 44.95 & 17.62 & 1020.2 & 1.96 & 3 & 140 & 100 & 17.6 & -4.86 \\
\hline IOF $290 \times 45 \times 15-N 50-U S H$ & 290.74 & 45.36 & 18.14 & 1120.6 & 2.49 & 3 & 140 & 50 & 28.34 & -7.63 \\
\hline IOF 290x45x15-N75-USH & 290.83 & 44.8 & 19.63 & 1145.1 & 2.48 & 3 & 140 & 75 & 29.64 & -10.10 \\
\hline IOF 290x45x15-N100-USH & 289.91 & 44.6 & 20.07 & 1170.2 & 2.48 & 3 & 140 & 100 & 30.26 & -12.54 \\
\hline \multicolumn{11}{|l|}{ Edge-stiffened hole } \\
\hline IOF 240x45x15-N50-ESH & 236.33 & 44.76 & 17.44 & 969.3 & 1.97 & 3 & 140 & 50 & 16.26 & 1.18 \\
\hline IOF 240x45x15-N75-ESH & 236.67 & 44.75 & 17.77 & 994.3 & 1.98 & 3 & 140 & 75 & 17.54 & 1.39 \\
\hline IOF 240x45x15-N100-ESH & 237.67 & 45.01 & 17.67 & 1020.9 & 1.97 & 3 & 140 & 100 & 18.83 & 1.78 \\
\hline IOF 290x45x15-N50-ESH & 290.11 & 45.28 & 18.14 & 1120.2 & 2.48 & 3 & 140 & 50 & 30.07 & -1.99 \\
\hline IOF 290x45x15-N75-ESH & 290.54 & 44.78 & 19.71 & 1145.7 & 2.48 & 3 & 140 & 75 & 32.05 & -2.79 \\
\hline IOF 290x45x15-N100-ESH & 289.33 & 44.59 & 20.08 & 1170.3 & 2.49 & 3 & 140 & 100 & 33.62 & -2.83 \\
\hline
\end{tabular}


Table 2 Measured specimen dimensions and experimental ultimate loads for end-one-flange loading condition (EOF)

\begin{tabular}{|c|c|c|c|c|c|c|c|c|c|c|}
\hline Specimen & $\begin{array}{l}\text { Web } \\
d \\
(\mathrm{~mm})\end{array}$ & $\begin{array}{c}b_{f} \\
(\mathrm{~mm})\end{array}$ & $\begin{array}{c}b_{l} \\
(\mathrm{~mm})\end{array}$ & $\begin{array}{c}L \\
(\mathrm{~mm})\end{array}$ & $\begin{array}{c}t \\
(\mathrm{~mm})\end{array}$ & $\begin{array}{c}r_{i} \\
(\mathrm{~mm})\end{array}$ & $\begin{array}{c}a \\
(\mathrm{~mm})\end{array}$ & $\begin{array}{c}N \\
(\mathrm{~mm})\end{array}$ & $\begin{array}{c}\text { Exp.load } \\
\text { (Per web ) } \\
P_{E X P} \\
(\mathrm{kN})\end{array}$ & $\begin{array}{l}\text { Percentage of strength reduction } \\
\text { due to web holes } \\
R \\
(\%)\end{array}$ \\
\hline \multicolumn{11}{|l|}{ Plain section } \\
\hline EOF 240x45x15-N50-NH & 237.33 & 44.35 & 17.72 & 920.0 & 1.97 & 3 & - & 50 & 5.82 & - \\
\hline EOF 240x45x15-N75-NH & 237.21 & 44.97 & 17.78 & 970.1 & 1.97 & 3 & - & 75 & 6.41 & - \\
\hline EOF $240 \times 45 \times 15-\mathrm{N} 100-\mathrm{NH}$ & 237.58 & 45.1 & 17.81 & 1019.5 & 1.98 & 3 & - & 100 & 6.90 & - \\
\hline EOF 290x45x15-N50-NH & 290.33 & 45.1 & 18.92 & 1069.5 & 2.47 & 3 & - & 50 & 10.50 & - \\
\hline EOF 290x45x15-N75-NH & 290.67 & 45.31 & 18.59 & 1121.2 & 2.47 & 3 & - & 75 & 11.10 & - \\
\hline EOF $290 \times 45 \times 15-\mathrm{N} 100-\mathrm{NH}$ & 290.5 & 45.1 & 18.93 & 1170.4 & 2.47 & 3 & - & 100 & 11.70 & - \\
\hline \multicolumn{11}{|l|}{ Unstiffened hole } \\
\hline EOF 240x45x15-N50-USH & 236.73 & 44.84 & 17.48 & 920.1 & 1.96 & 3 & 140 & 50 & 4.22 & -27.49 \\
\hline EOF 240x45x15-N75-USH & 235.28 & 44.84 & 17.81 & 970.7 & 1.98 & 3 & 140 & 75 & 4.60 & -28.24 \\
\hline EOF $240 \times 45 \times 15-N 100-U S H$ & 236.32 & 45.1 & 17.78 & 1019.2 & 1.98 & 3 & 140 & 100 & 4.95 & -28.26 \\
\hline EOF 290x45x15-N50-USH & 290.13 & 45.56 & 17.87 & 1070.6 & 2.46 & 3 & 140 & 50 & 8.40 & -20.00 \\
\hline EOF $290 \times 45 \times 15-N 75-U S H$ & 290.43 & 45.28 & 18.51 & 1121.9 & 2.46 & 3 & 140 & 75 & 8.95 & -19.37 \\
\hline EOF 290x45x15-N100-USH & 290.72 & 45 & 20 & 1170.6 & 2.46 & 3 & 140 & 100 & 9.48 & -18.97 \\
\hline \multicolumn{11}{|l|}{ Edge-stiffened hole } \\
\hline EOF 240x45x15-N50-ESH & 238 & 44.93 & 17.74 & 919.3 & 1.98 & 3 & 140 & 50 & 5.74 & -1.37 \\
\hline EOF $240 \times 45 \times 15-N 75-E S H$ & 236.83 & 44.57 & 17.55 & 969.5 & 1.97 & 3 & 140 & 75 & 6.30 & -1.72 \\
\hline EOF 240x45x15-N100-ESH & 237.5 & 44.8 & 17.47 & 1020.9 & 1.98 & 3 & 140 & 100 & 6.80 & -1.45 \\
\hline EOF 290x45x15-N50-ESH & 290.11 & 45.43 & 17.63 & 1070.2 & 2.48 & 3 & 140 & 50 & 10.40 & -0.95 \\
\hline EOF $290 \times 45 \times 15-N 75-E S H$ & 289.5 & 45.08 & 18.19 & 1120.5 & 2.48 & 3 & 140 & 75 & 10.96 & -1.26 \\
\hline EOF 290x45x15-N100-ESH & 289.83 & 45.06 & 18.87 & 1170.4 & 2.47 & 3 & 140 & 100 & 11.52 & -1.54 \\
\hline
\end{tabular}


Table 3 Material properties of specimens

\begin{tabular}{llll}
\hline & Section & $\sigma_{0.2}(\mathrm{MPa})$ & $\sigma_{u}(\mathrm{MPa})$ \\
\hline \multirow{2}{*}{$240 \times 45 \times 15-\mathrm{t} 1.85$} & 1 & 264.82 & 284.78 \\
& 2 & 268.81 & 283.75 \\
& 3 & 263.39 & 287.81 \\
\hline \multirow{2}{*}{$290 \times 45 \times 15-\mathrm{t} 2.5$} & 1 & 318.92 & 410.23 \\
& 2 & 328.62 & 413.31 \\
& 3 & 332.81 & 414.48 \\
\hline
\end{tabular}


Table 4 Comparison of the web crippling strength predicted from the finite element analysis with the experiment results for IOF loading condition

\begin{tabular}{|c|c|c|c|c|c|}
\hline Specimen & $\begin{array}{l}\text { Web slenderness, } \\
(h / t)\end{array}$ & $\begin{array}{l}\text { Web hole ratio, } \\
(a / h)\end{array}$ & $\begin{array}{l}\text { Exp. load per web, } \\
P_{\text {EXP }}(\mathrm{kN})\end{array}$ & $\begin{array}{l}\text { Web crippling strength per web } \\
\text { predicted from FEA, } P_{\mathrm{FEA}}(\mathrm{kN})\end{array}$ & $\begin{array}{l}\text { Comparison, } \\
P_{\text {EXP }} / P_{\text {FEA }}\end{array}$ \\
\hline \multicolumn{6}{|l|}{ Plain section } \\
\hline IOF $240 \times 45 \times 15-\mathrm{N} 50-\mathrm{NH}$ & 118.0 & 0 & 16.07 & 16.20 & 0.99 \\
\hline IOF $240 \times 45 \times 15-\mathrm{N} 75-\mathrm{NH}$ & 118.9 & 0 & 17.3 & 17.50 & 0.99 \\
\hline IOF $240 \times 45 \times 15-\mathrm{N} 100-\mathrm{NH}$ & 118.6 & 0 & 18.5 & 18.70 & 0.99 \\
\hline IOF $290 \times 45 \times 15-N 50-\mathrm{NH}$ & 114.7 & 0 & 30.68 & 31.20 & 0.98 \\
\hline IOF 290x45x15-N75-NH & 114.8 & 0 & 32.97 & 33.89 & 0.97 \\
\hline \multicolumn{6}{|l|}{ Unstiffened hole } \\
\hline IOF $240 \times 45 \times 15-N 50-U S H$ & 117.4 & 0.6 & 15.72 & 15.96 & 0.98 \\
\hline IOF 240x45x15-N75-USH & 117.5 & 0.6 & 16.64 & 16.84 & 0.99 \\
\hline IOF $240 \times 45 \times 15-\mathrm{N} 100-\mathrm{USH}$ & 118.2 & 0.6 & 17.6 & 17.80 & 0.99 \\
\hline IOF 290x45x15-N50-USH & 114.8 & 0.5 & 28.34 & 29.02 & 0.98 \\
\hline IOF 290x45x15-N75-USH & 115.3 & 0.5 & 29.64 & 30.81 & 0.96 \\
\hline IOF $290 \times 45 \times 15-N 100-U S H$ & 114.9 & 0.5 & 30.26 & 32.14 & 0.94 \\
\hline \multicolumn{6}{|l|}{ Edge-stiffened hole } \\
\hline IOF 240x45x15-N50-ESH & 118.0 & 0.6 & 16.26 & 16.54 & 0.98 \\
\hline IOF 240x45x15-N75-ESH & 117.5 & 0.6 & 17.54 & 17.70 & 0.99 \\
\hline IOF 240x45x15-N100-ESH & 118.6 & 0.6 & 18.83 & 18.95 & 0.99 \\
\hline IOF 290x45x15-N50-ESH & 115.0 & 0.5 & 30.07 & 29.87 & 1.01 \\
\hline IOF 290x45x15-N75-ESH & 115.2 & 0.5 & 32.05 & 31.42 & 1.02 \\
\hline IOF $290 \times 45 \times 15-N 100-E S H$ & 114.2 & 0.5 & 33.62 & 33.10 & 1.02 \\
\hline Mean & & & & & 0.99 \\
\hline $\mathrm{COV}$ & & & & & 0.02 \\
\hline
\end{tabular}


Table 5 Comparison of the web crippling strength predicted from the finite element analysis with the experiment results for EOF loading condition

\begin{tabular}{|c|c|c|c|c|c|}
\hline Specimen & $\begin{array}{l}\text { Web slenderness, } \\
(h / t)\end{array}$ & $\begin{array}{l}\text { Web hole ratio, } \\
(a / h)\end{array}$ & $\begin{array}{l}\text { Exp. load per web, } \\
P_{\text {EXP }(\mathrm{kN})}\end{array}$ & $\begin{array}{l}\text { Web crippling strength per web } \\
\text { predicted from FEA, } P_{\text {FEA }}(\mathrm{kN})\end{array}$ & $\begin{array}{l}\text { Comparison, } \\
P_{\text {EXP }} / P_{\text {FEA }}\end{array}$ \\
\hline \multicolumn{6}{|l|}{ Plain section } \\
\hline EOF 240x45x15-N50-NH & 118.5 & 0 & 5.82 & 5.81 & 1.00 \\
\hline EOF $240 \times 45 \times 15-N 75-N H$ & 118.3 & 0 & 6.41 & 6.49 & 0.99 \\
\hline EOF $240 \times 45 \times 15-N 100-\mathrm{NH}$ & 117.7 & 0 & 6.9 & 7.01 & 0.98 \\
\hline EOF 290x45x15-N50-NH & 115.5 & 0 & 10.5 & 10.65 & 0.99 \\
\hline EOF 290x45x15-N75-NH & 115.7 & 0 & 11.1 & 11.26 & 0.99 \\
\hline \multicolumn{6}{|l|}{ Unstiffened hole } \\
\hline EOF 240x45x15-N50-USH & 118.4 & 0.6 & 4.22 & 4.42 & 0.95 \\
\hline EOF 240x45x15-N75-USH & 116.7 & 0.6 & 4.6 & 4.80 & 0.96 \\
\hline EOF $240 \times 45 \times 15-N 100-U S H$ & 117.2 & 0.6 & 4.95 & 5.16 & 0.96 \\
\hline EOF 290x45x15-N50-USH & 115.9 & 0.5 & 8.4 & 8.72 & 0.96 \\
\hline EOF 290x45x15-N75-USH & 115.9 & 0.5 & 8.95 & 9.34 & 0.96 \\
\hline EOF $290 \times 45 \times 15-N 100-U S H$ & 115.9 & 0.5 & 9.48 & 9.86 & 0.96 \\
\hline \multicolumn{6}{|l|}{ Edge-stiffened hole } \\
\hline EOF 240x45x15-N50-ESH & 118.2 & 0.6 & 5.74 & 5.85 & 0.98 \\
\hline EOF 240x45x15-N75-ESH & 118.2 & 0.6 & 6.3 & 6.43 & 0.98 \\
\hline EOF 240x45x15-N100-ESH & 117.9 & 0.6 & 6.8 & 6.86 & 0.99 \\
\hline EOF 290x45x15-N50-ESH & 114.9 & 0.5 & 10.4 & 10.51 & 0.99 \\
\hline EOF 290x45x15-N75-ESH & 114.7 & 0.5 & 10.96 & 11.13 & 0.98 \\
\hline EOF 290x45x15-N100-ESH & 115.3 & 0.5 & 11.52 & 11.78 & 0.98 \\
\hline Mean & & & & & 0.98 \\
\hline $\mathrm{COV}$ & & & & & 0.01 \\
\hline
\end{tabular}


Table 6 Dimensions and web crippling strengths predicted from finite element analysis of parametric study for IOF loading condition

\begin{tabular}{|c|c|c|c|c|c|c|c|c|c|}
\hline \multirow[t]{3}{*}{ Specimen } & \multirow[t]{3}{*}{$\begin{array}{l}\text { Flat web, } \\
h(\mathrm{~mm})\end{array}$} & \multirow[t]{3}{*}{$\begin{array}{l}\text { Thickness, } \\
t(\mathrm{~mm})\end{array}$} & \multirow[t]{3}{*}{$\begin{array}{l}\text { Web holes } \\
\text { ratio, } A(a / h)\end{array}$} & \multirow[t]{3}{*}{$\begin{array}{l}\text { Diameter of circular } \\
\text { web holes, } a(\mathrm{~mm})\end{array}$} & \multirow[t]{3}{*}{$\begin{array}{l}\text { Web holes distance } \\
\text { ratio, } X(x / h)\end{array}$} & \multirow[t]{3}{*}{$\begin{array}{l}\text { Distance of the web } \\
\text { holes to the near edge of } \\
\text { the bearing plate, } x(\mathrm{~mm})\end{array}$} & \multicolumn{3}{|c|}{$\begin{array}{l}\text { FEA load per web, } P_{\mathrm{FEA}} \\
(\mathrm{kN})\end{array}$} \\
\hline & & & & & & & \multicolumn{3}{|c|}{$\begin{array}{l}\text { Web holes edge-stiffener } \\
\text { length ratio, } Q(q / h)\end{array}$} \\
\hline & & & & & & & Q0.04 & Q0.06 & Q0.08 \\
\hline IOF 240-N50-A0 & 233.39 & 1.97 & 0.0 & 0.0 & 0 & 0.00 & 16.20 & 16.20 & 16.20 \\
\hline IOF 240-N50-X0.2-A0.4 & 233.39 & 1.97 & 0.4 & 93.62 & 0.2 & 46.68 & 16.86 & 16.91 & 16.97 \\
\hline IOF 240-N50-X0.2-A0.6 & 233.39 & 1.97 & 0.6 & 140.44 & 0.2 & 46.68 & 16.26 & 16.35 & 16.43 \\
\hline IOF $240-\mathrm{N} 50-\mathrm{X} 0.2-\mathrm{A} 0.8$ & 233.39 & 1.97 & 0.8 & 187.20 & 0.2 & 46.68 & 15.82 & 16.03 & 16.16 \\
\hline IOF 240-N50-X0.4-A0.4 & 233.39 & 1.97 & 0.4 & 93.62 & 0.4 & 93.36 & 16.78 & 16.83 & 16.87 \\
\hline IOF 240-N50-X0.4-A0.6 & 233.39 & 1.97 & 0.6 & 140.44 & 0.4 & 93.36 & 16.42 & 16.48 & 16.53 \\
\hline IOF 240-N50-X0.4-A0.8 & 233.39 & 1.97 & 0.8 & 187.20 & 0.4 & 93.36 & 15.73 & 15.91 & 16.02 \\
\hline IOF 240-N50-X0.6-A0.4 & 233.39 & 1.97 & 0.4 & 93.62 & 0.6 & 140.40 & 16.81 & 16.84 & 16.88 \\
\hline IOF 240-N50-X0.6-A0.6 & 233.39 & 1.97 & 0.6 & 140.44 & 0.6 & 140.40 & 16.61 & 16.66 & 16.71 \\
\hline IOF 240-N50-X0.6-A0.8 & 233.39 & 1.97 & 0.8 & 187.20 & 0.6 & 140.40 & 16.25 & 16.40 & 16.49 \\
\hline
\end{tabular}


Table 7 Dimensions and web crippling strengths predicted from finite element analysis of parametric study for EOF loading condition

\begin{tabular}{|c|c|c|c|c|c|c|c|c|c|}
\hline \multirow[t]{3}{*}{ Specimen } & \multirow[t]{3}{*}{$\begin{array}{l}\text { Flat web, } \\
h(\mathrm{~mm})\end{array}$} & \multirow[t]{3}{*}{$\begin{array}{l}\text { Thickness, } \\
t(\mathrm{~mm})\end{array}$} & \multirow[t]{3}{*}{$\begin{array}{l}\text { Web holes } \\
\text { ratio, } A(a / h)\end{array}$} & \multirow[t]{3}{*}{$\begin{array}{l}\text { Diameter of circular } \\
\text { web holes, } a(\mathrm{~mm})\end{array}$} & \multirow[t]{3}{*}{$\begin{array}{l}\text { Web holes distance } \\
\text { ratio, } X(x / h)\end{array}$} & \multirow[t]{3}{*}{$\begin{array}{l}\text { Distance of the web } \\
\text { holes to the near edge of } \\
\text { the bearing plate, } x(\mathrm{~mm})\end{array}$} & \multicolumn{3}{|c|}{$\begin{array}{l}\text { FEA load per web, } P_{\text {FEA }} \\
(\mathrm{kN})\end{array}$} \\
\hline & & & & & & & \multicolumn{3}{|c|}{$\begin{array}{l}\text { Web holes edge-stiffener } \\
\text { length ratio, } Q(q / h)\end{array}$} \\
\hline & & & & & & & Q0.04 & Q0.06 & Q0.08 \\
\hline EOF $240-\mathrm{N} 50-\mathrm{A} 0$ & 233.39 & 1.97 & 0.0 & 0.0 & 0 & 0.00 & 5.81 & 5.81 & 5.81 \\
\hline EOF 240-N50-X0.2-A0.4 & 233.39 & 1.97 & 0.4 & 93.4 & 0.2 & 46.68 & 5.89 & 5.91 & 5.93 \\
\hline EOF 240-N50-X0.2-A0.6 & 233.39 & 1.97 & 0.6 & 140.0 & 0.2 & 46.68 & 5.76 & 5.81 & 5.85 \\
\hline EOF 240-N50-X0.2-A0.8 & 233.39 & 1.97 & 0.8 & 186.7 & 0.2 & 46.68 & 5.22 & 5.36 & 5.45 \\
\hline EOF 240-N50-X0.4-A0.4 & 233.39 & 1.97 & 0.4 & 93.4 & 0.4 & 93.36 & 5.77 & 5.78 & 5.80 \\
\hline EOF 240-N50-X0.4-A0.6 & 233.39 & 1.97 & 0.6 & 140.0 & 0.4 & 93.36 & 5.58 & 5.63 & 5.67 \\
\hline EOF 240-N50-X0.4-A0.8 & 233.39 & 1.97 & 0.8 & 186.7 & 0.4 & 93.36 & 5.23 & 5.32 & 5.39 \\
\hline EOF 240-N50-X0.6-A0.4 & 233.39 & 1.97 & 0.4 & 93.4 & 0.6 & 140.03 & 5.68 & 5.70 & 5.72 \\
\hline EOF 240-N50-X0.6-A0.6 & 233.39 & 1.97 & 0.6 & 140.0 & 0.6 & 140.03 & 5.53 & 5.57 & 5.60 \\
\hline EOF 240-N50-X0.6-A0.8 & 233.39 & 1.97 & 0.8 & 186.7 & 0.6 & 140.03 & 5.29 & 5.37 & 5.41 \\
\hline
\end{tabular}




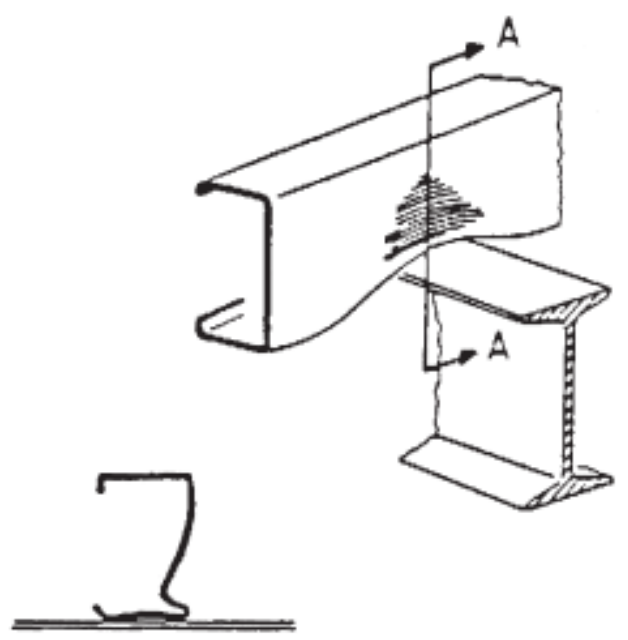

Section A-A

Fig.1 Web crippling at a support point [1]

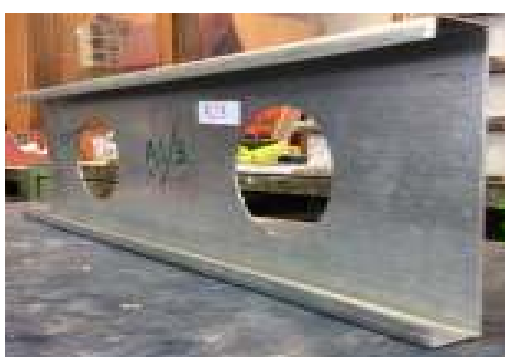

(a) Section with unstiffened holes

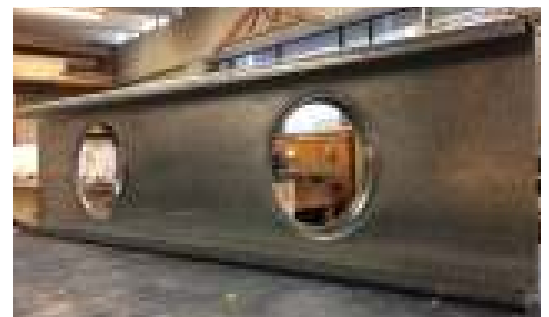

(b) Section with edge-stiffened holes

Fig.2 Cold-formed steel channel sections with web openings 

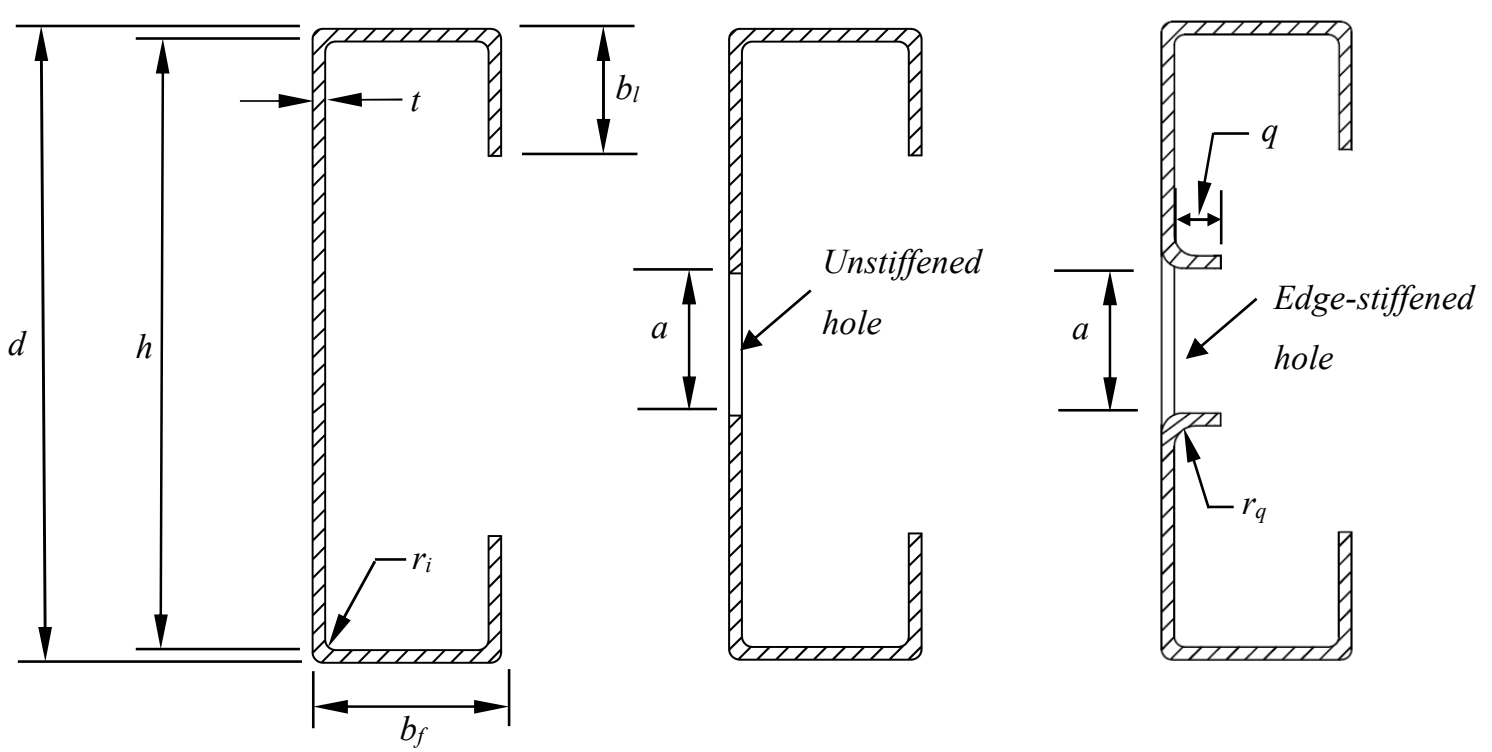

(a) No hole

(b) Unstiffened hole

(c) Edge-stiffened hole

Fig.3 Definition of symbols

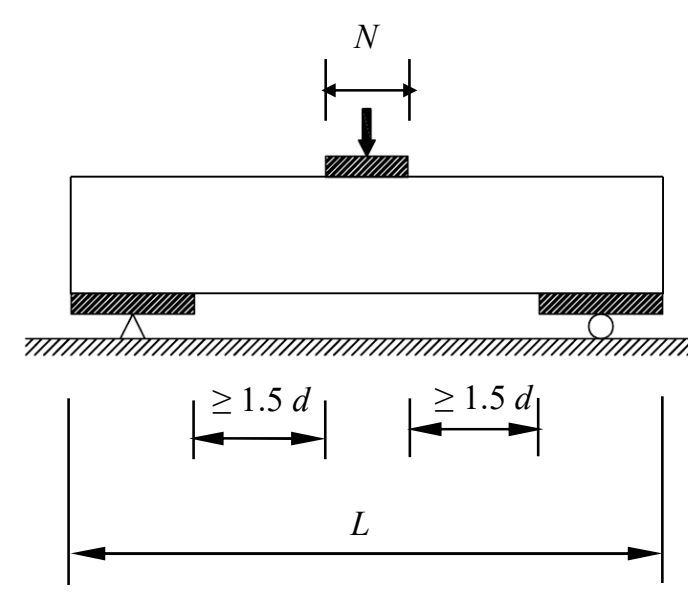

(a) Without holes
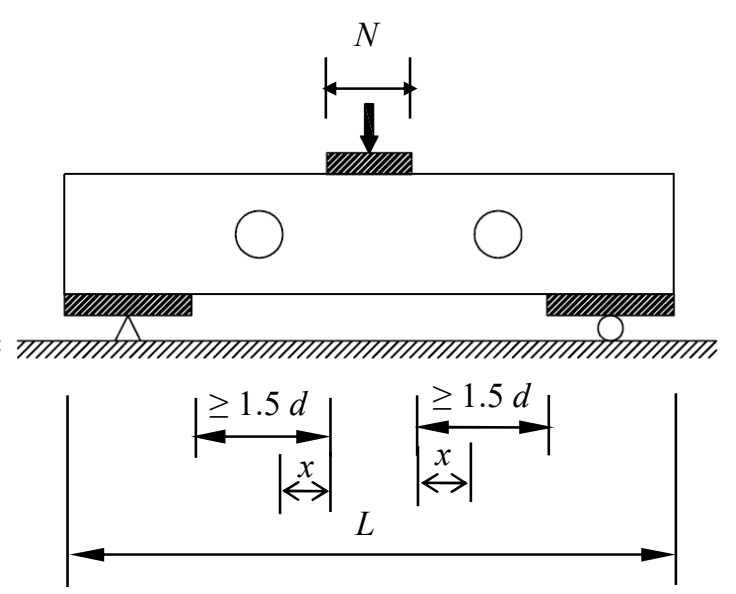

(b) With holes

Fig.4 IOF loading condition

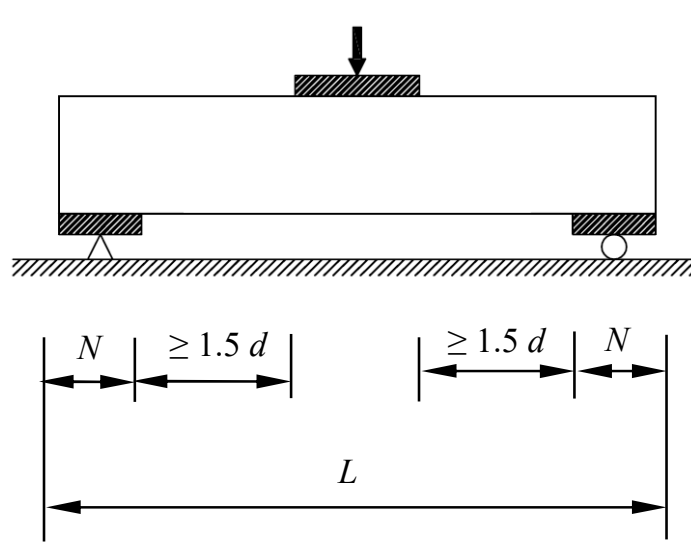

(a) Without holes

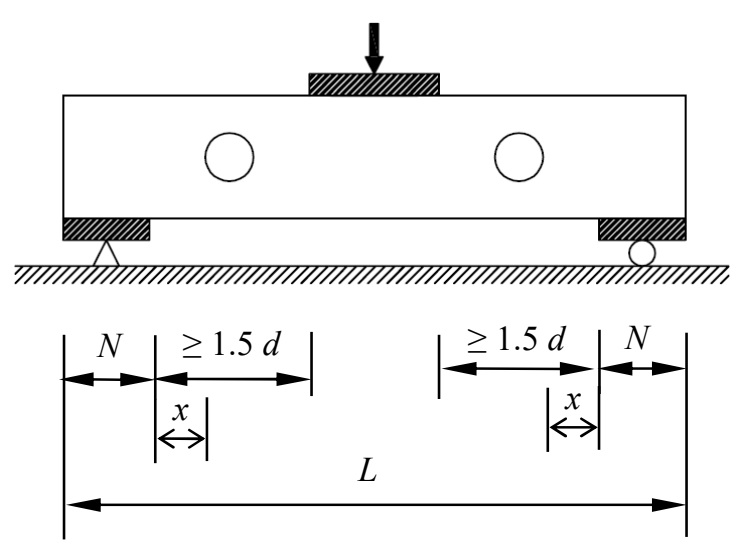

(b) With holes

Fig.5 EOF loading condition 


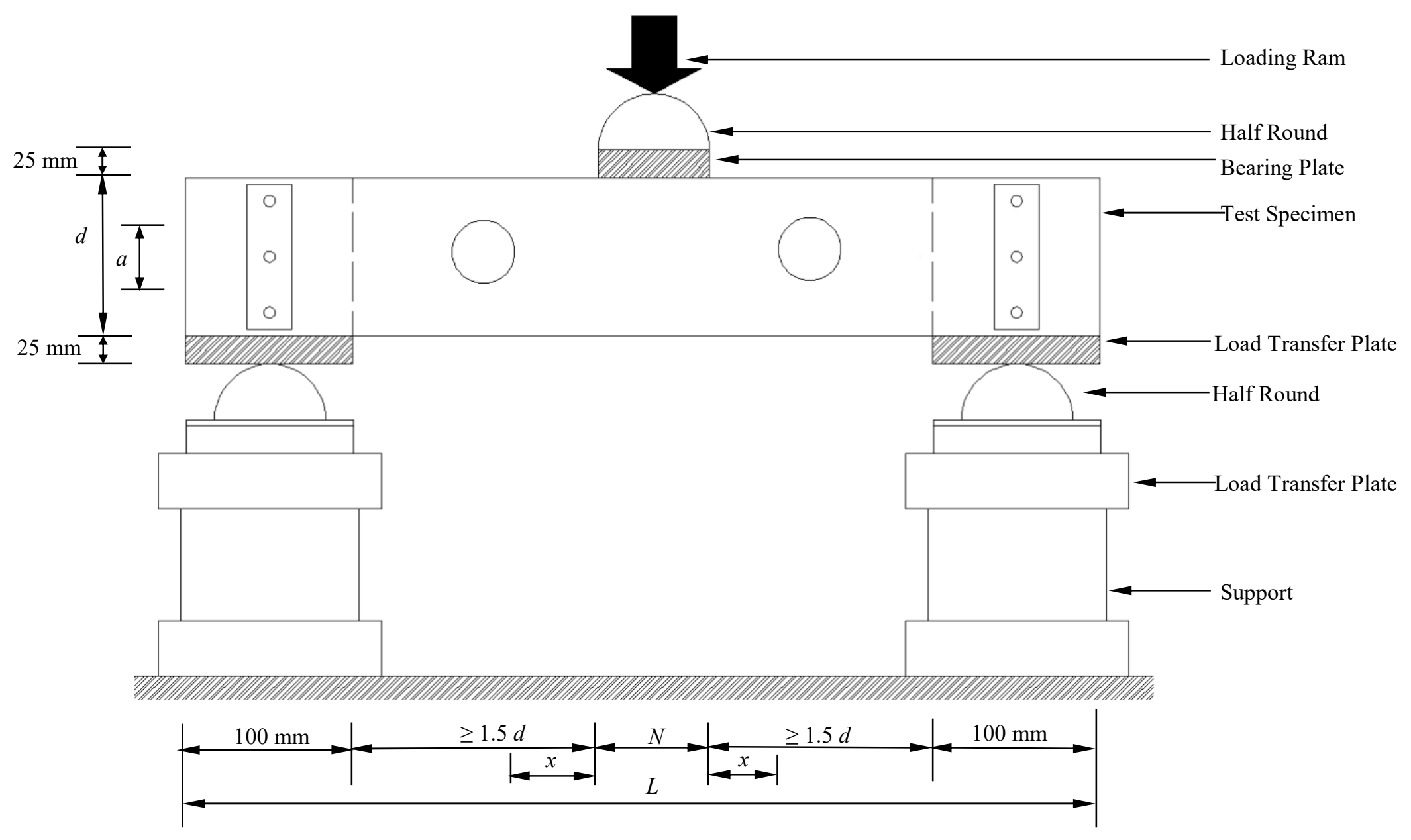

(a) Front view of with a horizontal clear distance to near edge of bearing plate 


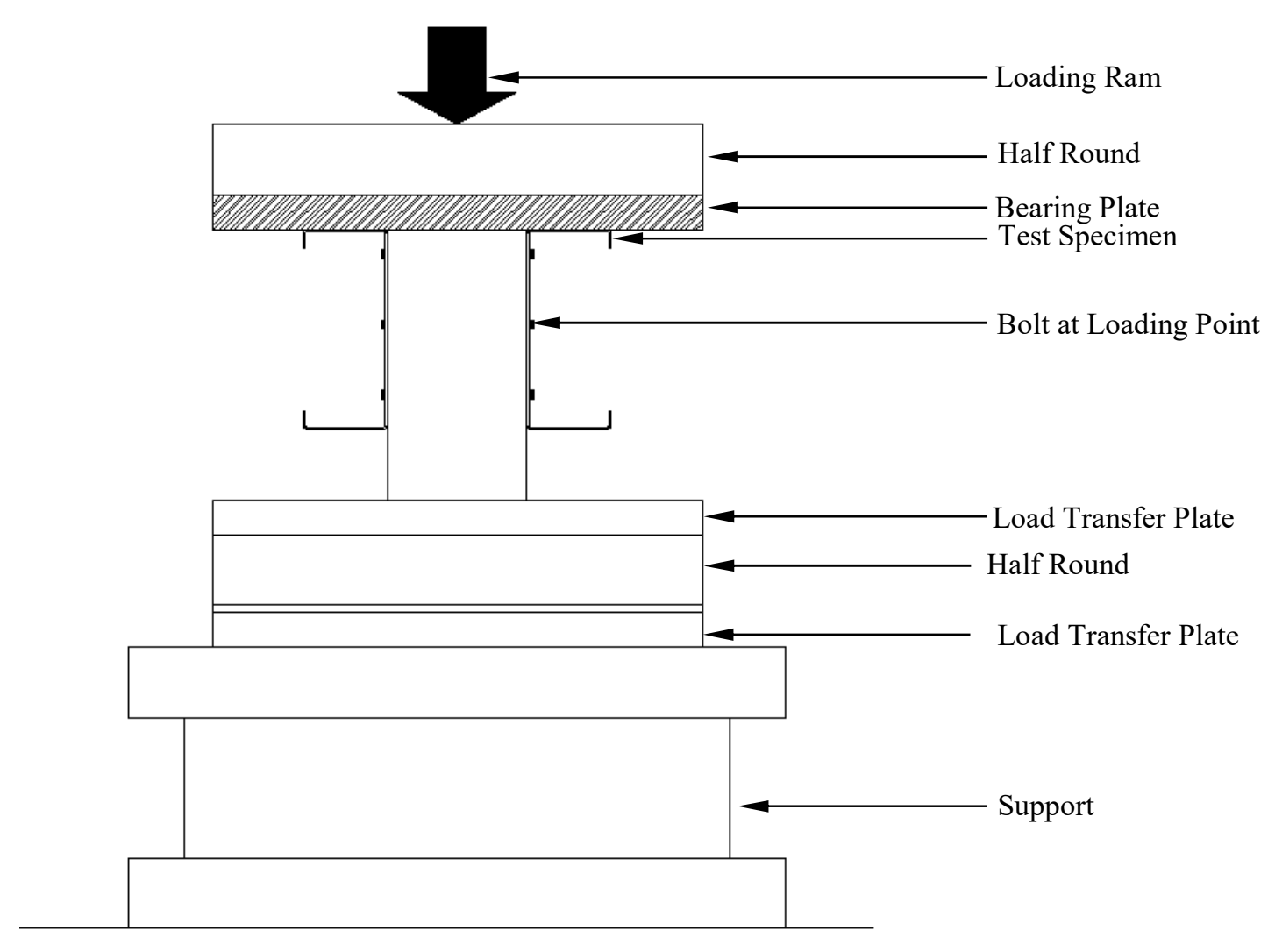

(b) End view

Fig.6 Schematic view of test set-up for IOF loading condition 

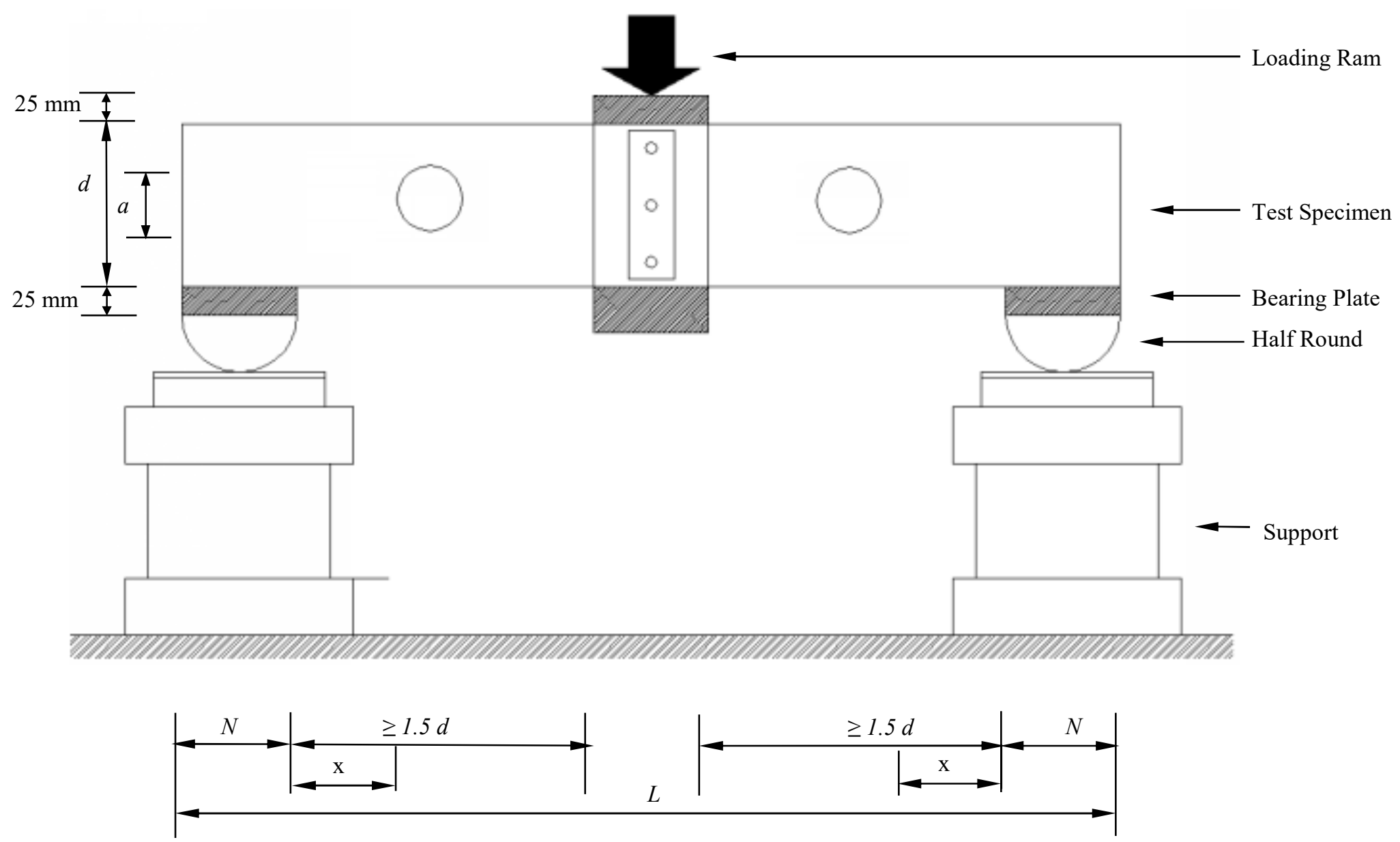

(a) Front view of with a horizontal clear distance to near edge of bearing plates 


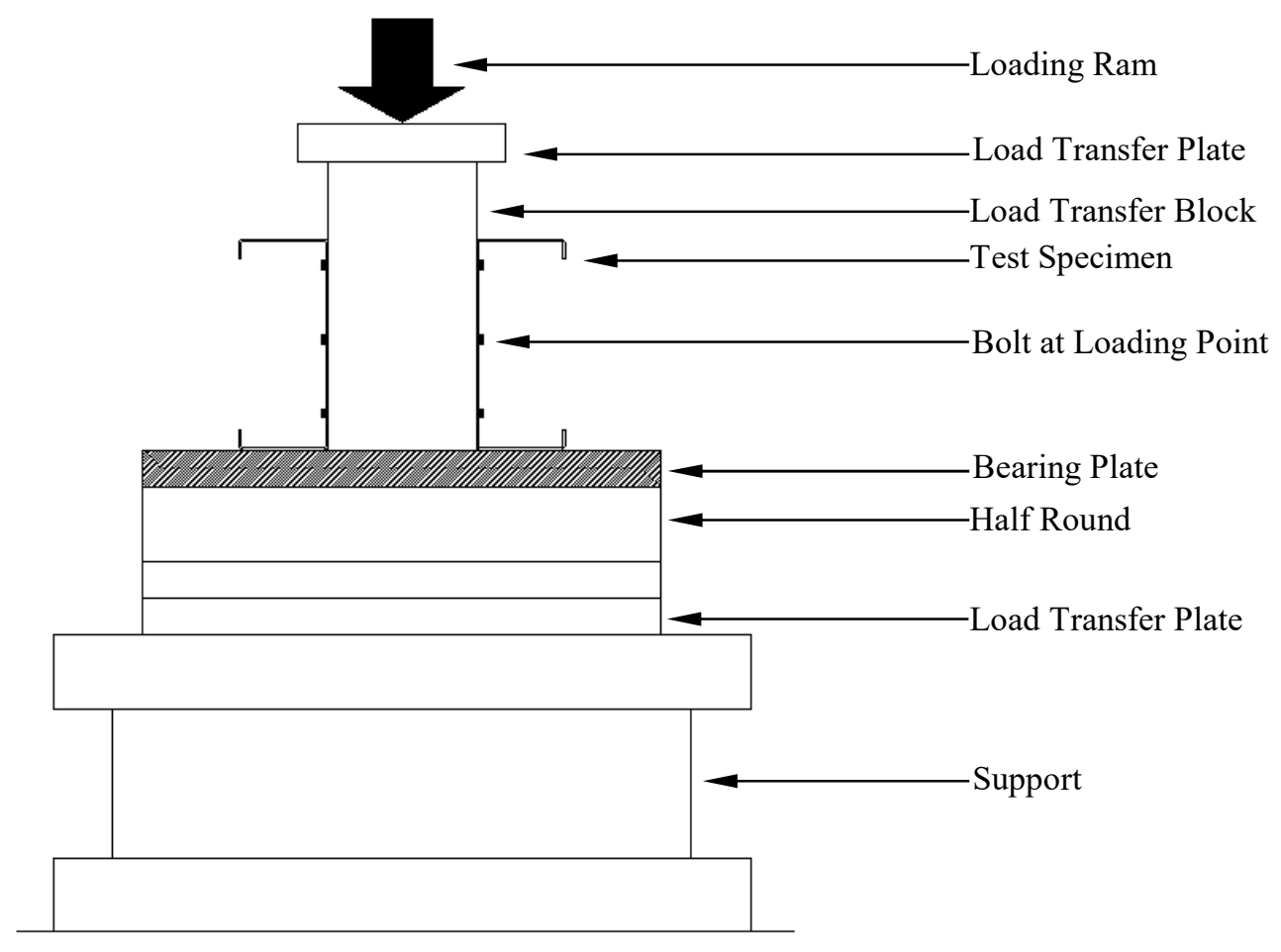

(b) End View

Fig.7 Schematic view of test set-up for EOF loading condition 


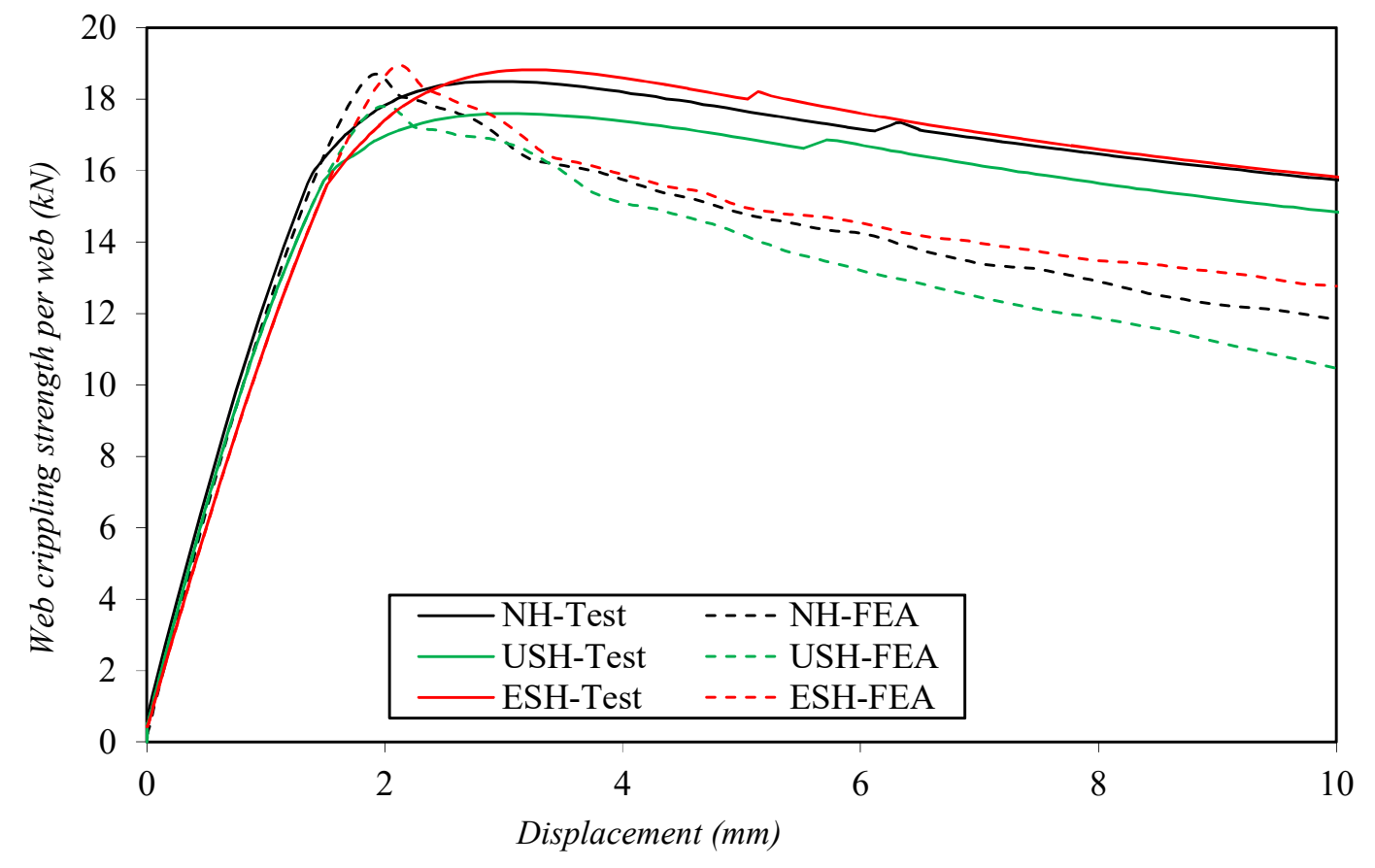

a) IOF loading condition (Specimens $240 \times 45 \times 1.8-\mathrm{N} 100$ )

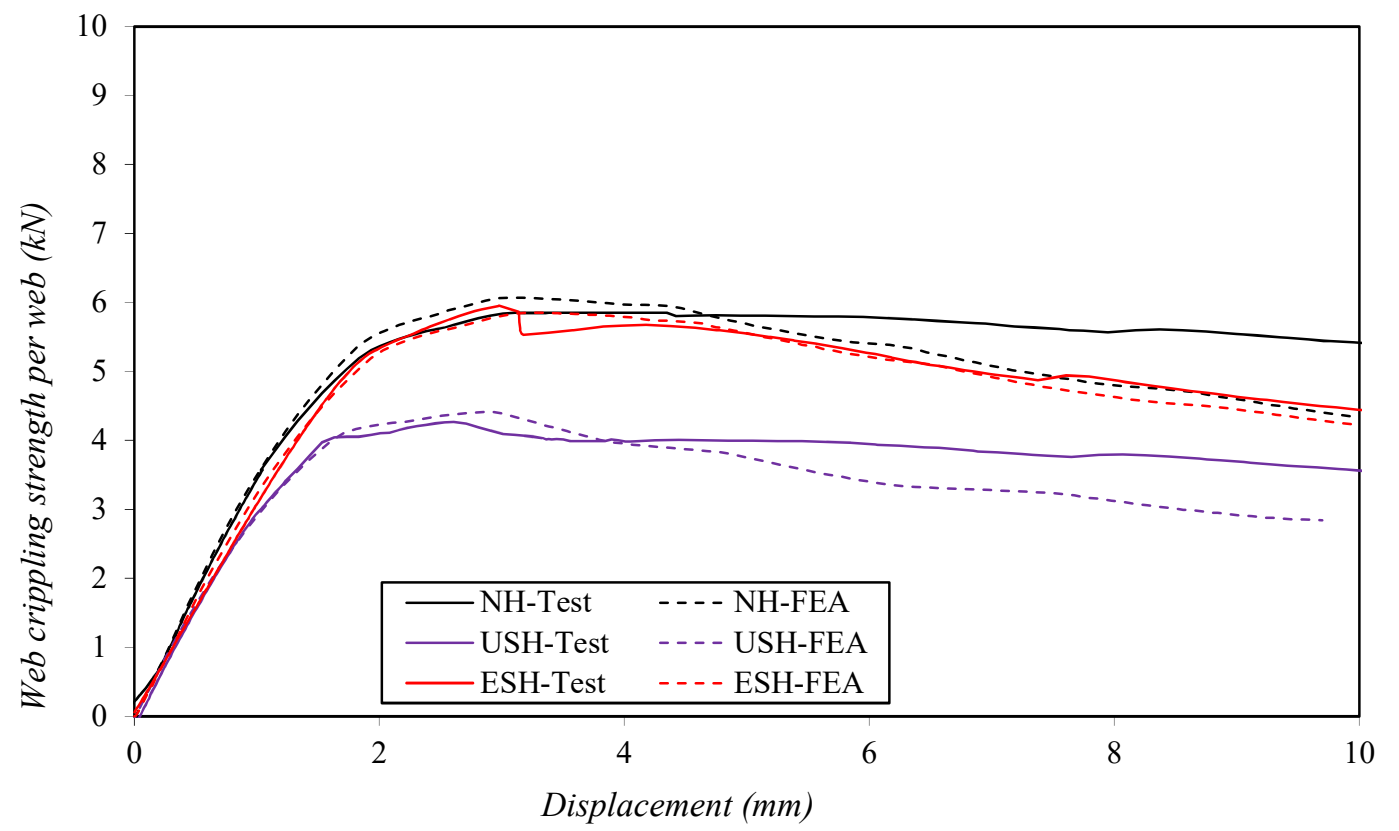

(b) EOF loading condition (Specimens $240 \times 45 \times 1.8-\mathrm{N} 50$ )

Fig.8 Comparison of experiment and finite element analysis web deformation curves 


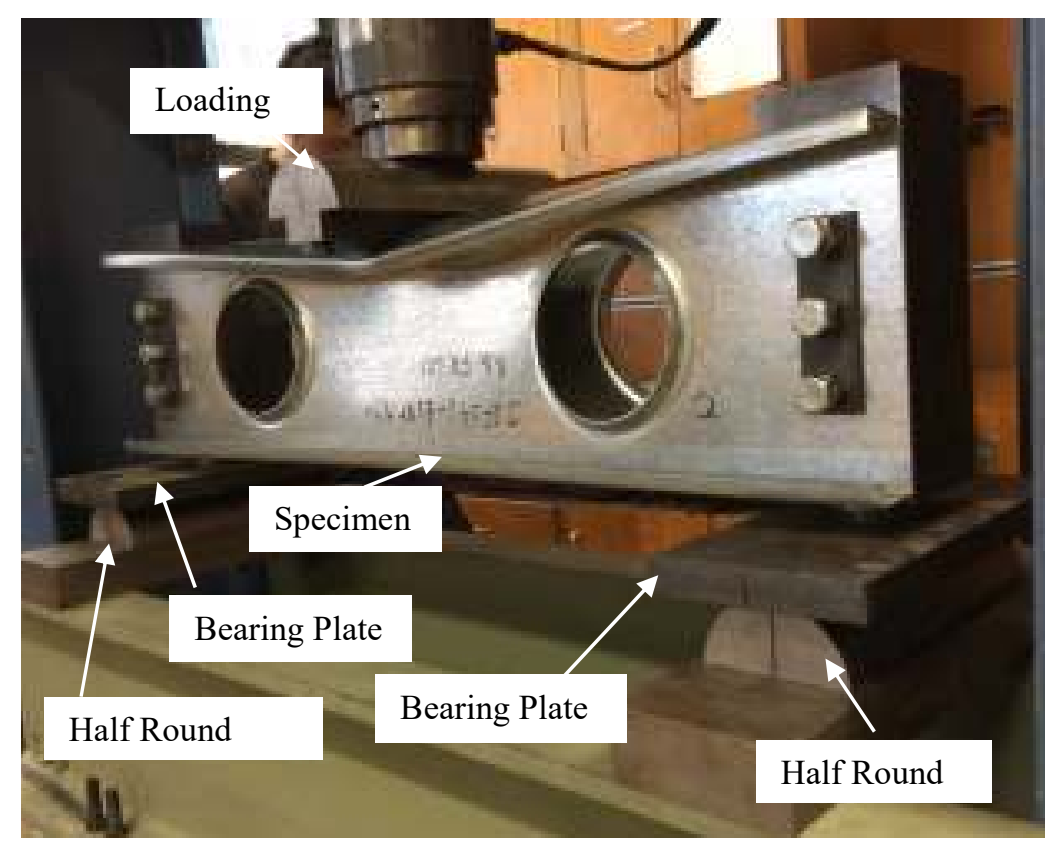

(a) Experimental

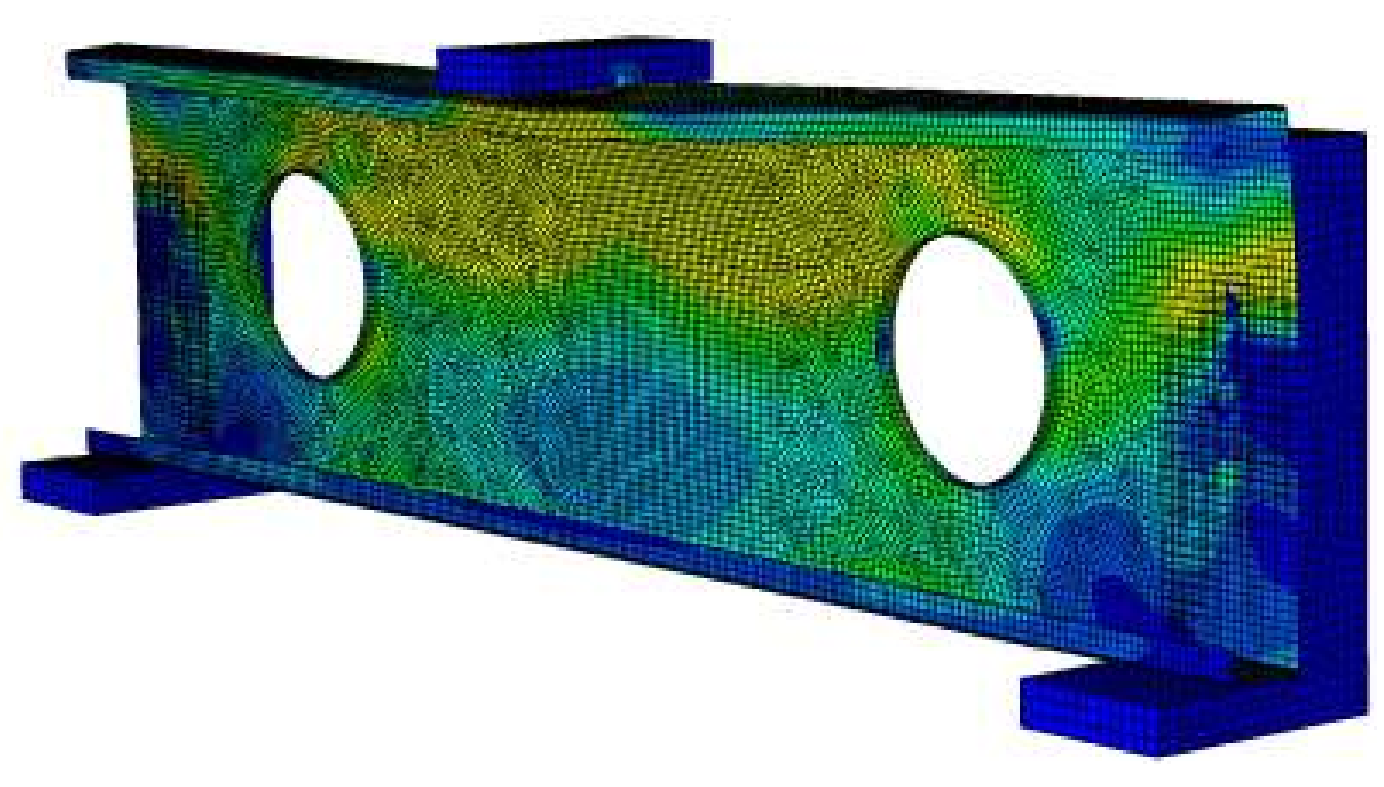

(b) FEA

Fig.9 Comparison of experiment and finite element analysis for IOF loading condition 


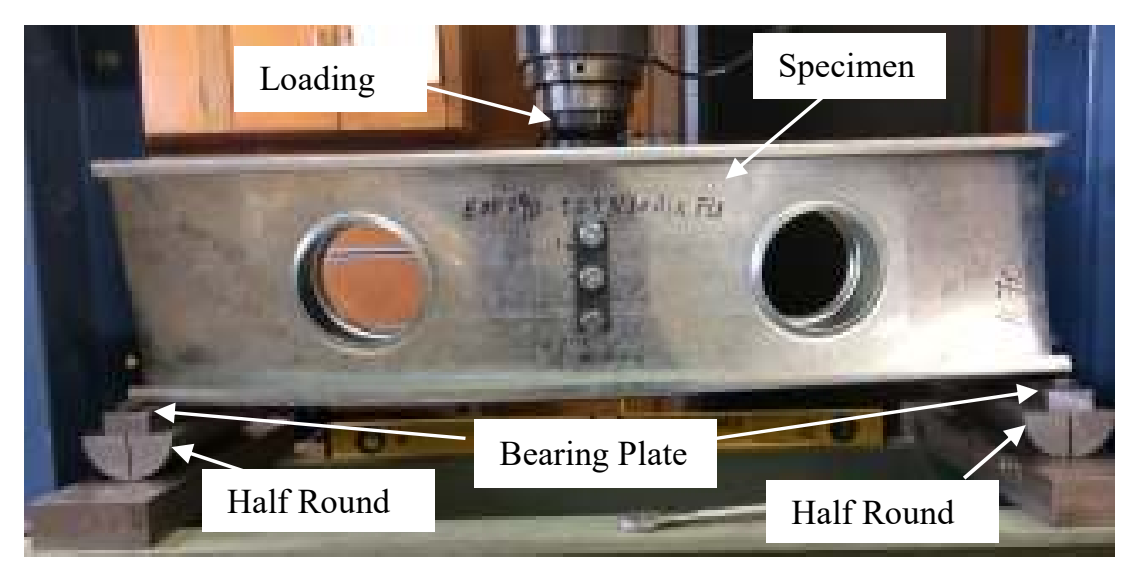

(a) Experimental

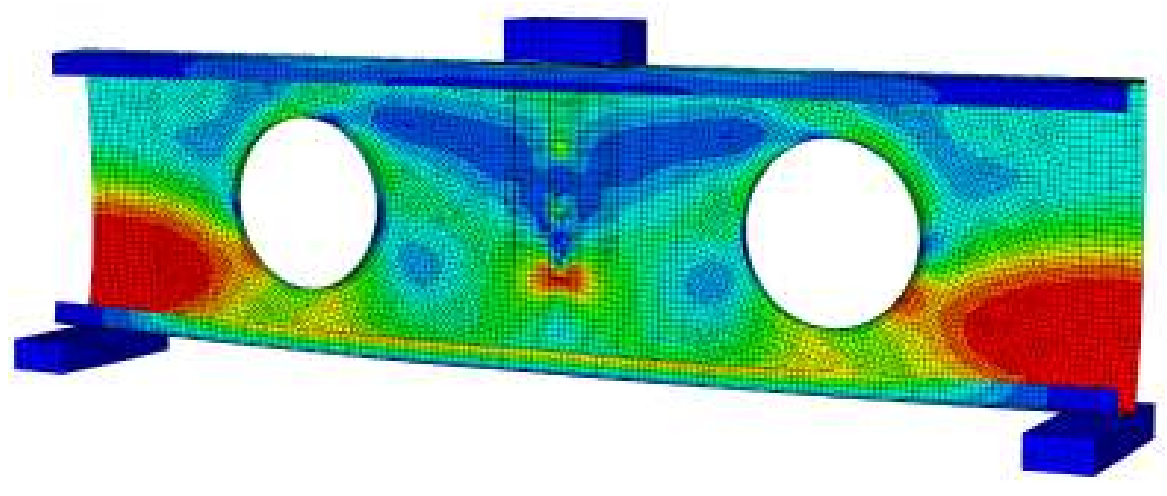

(b) FEA

Fig.10 Comparison of experiment and finite element analysis for EOF loading condition 


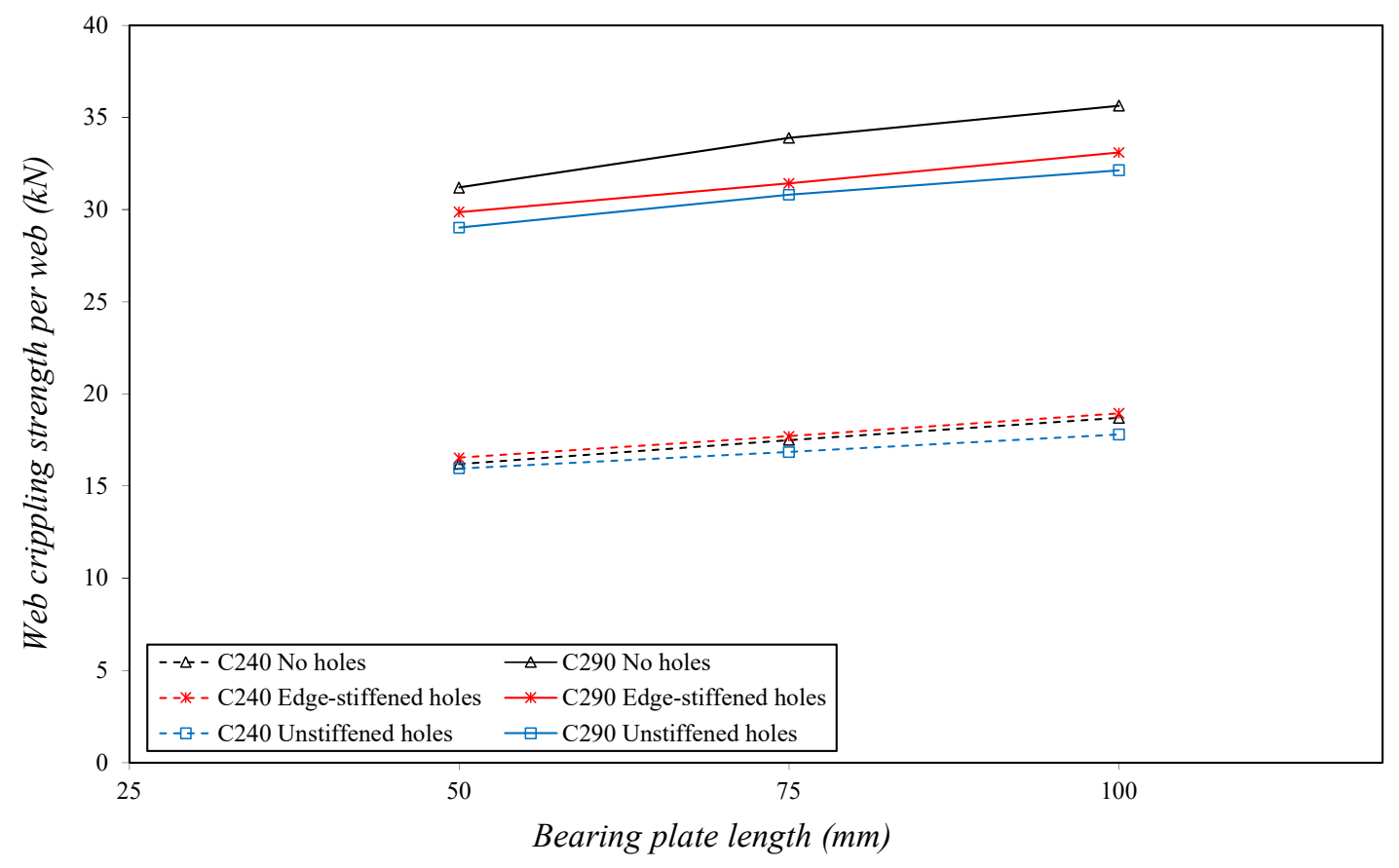

a) IOF loading condition

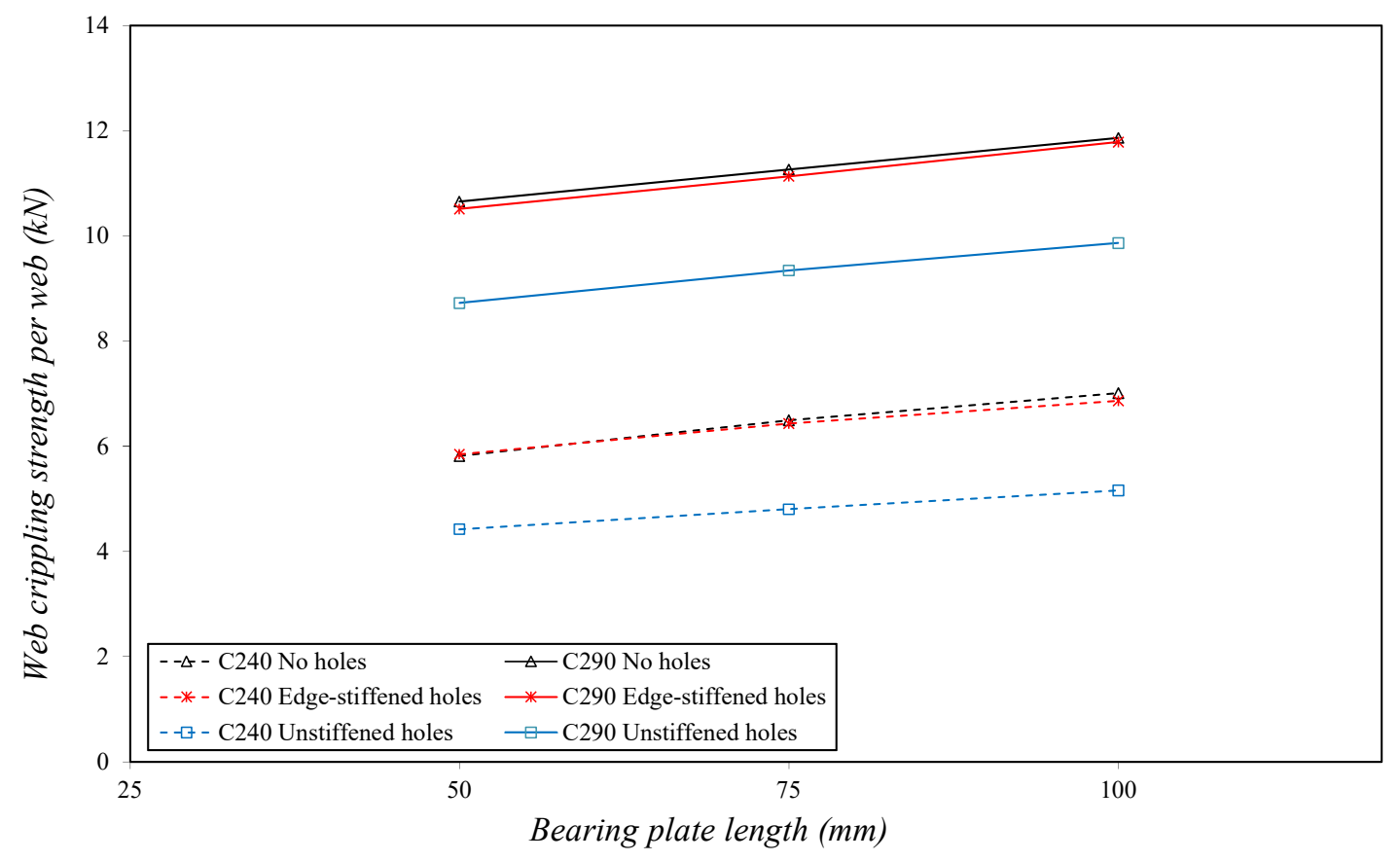

(b) EOF loading condition

Fig.11 Variation of web crippling strength due to with and without web holes 


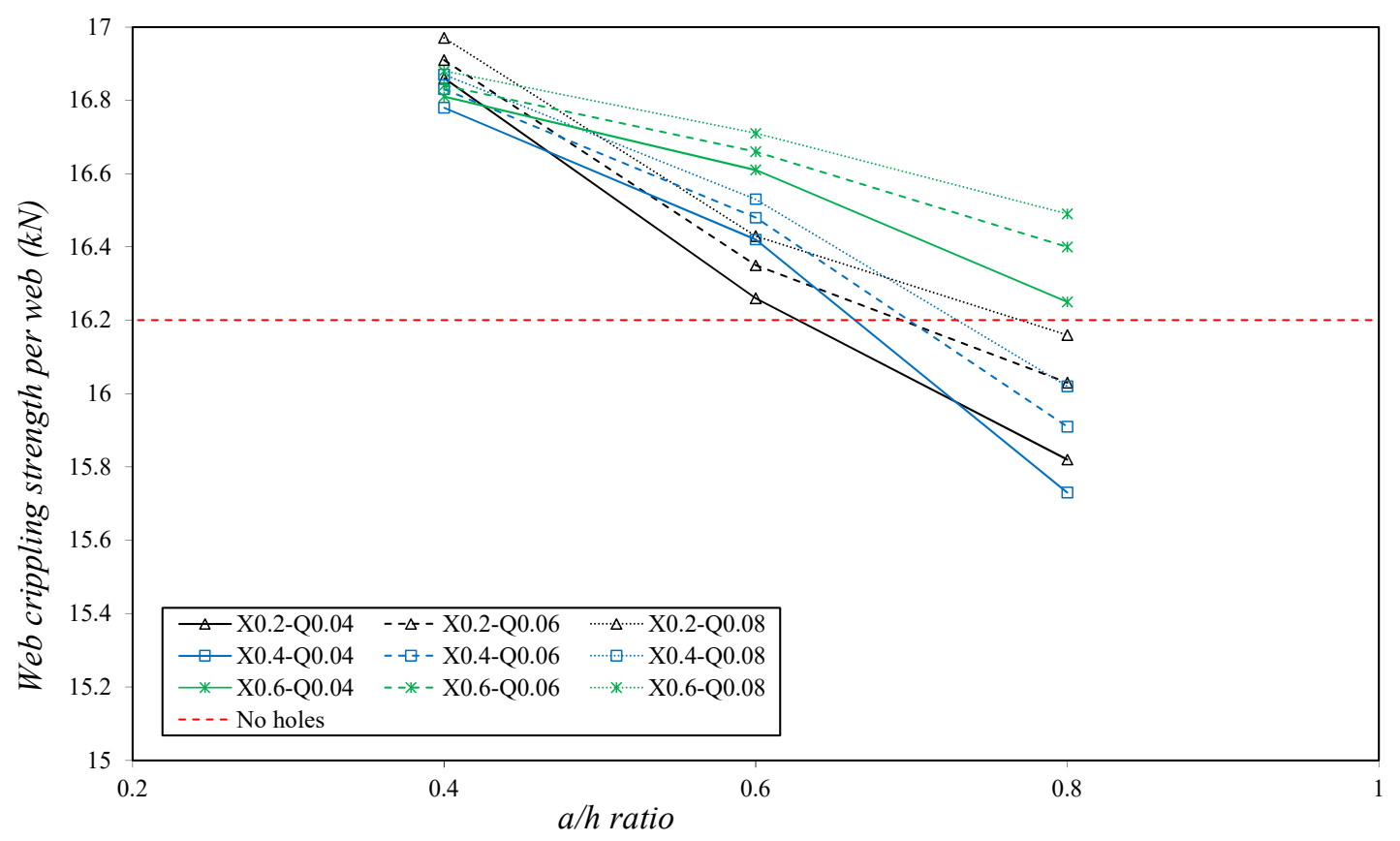

(a) IOF loading condition

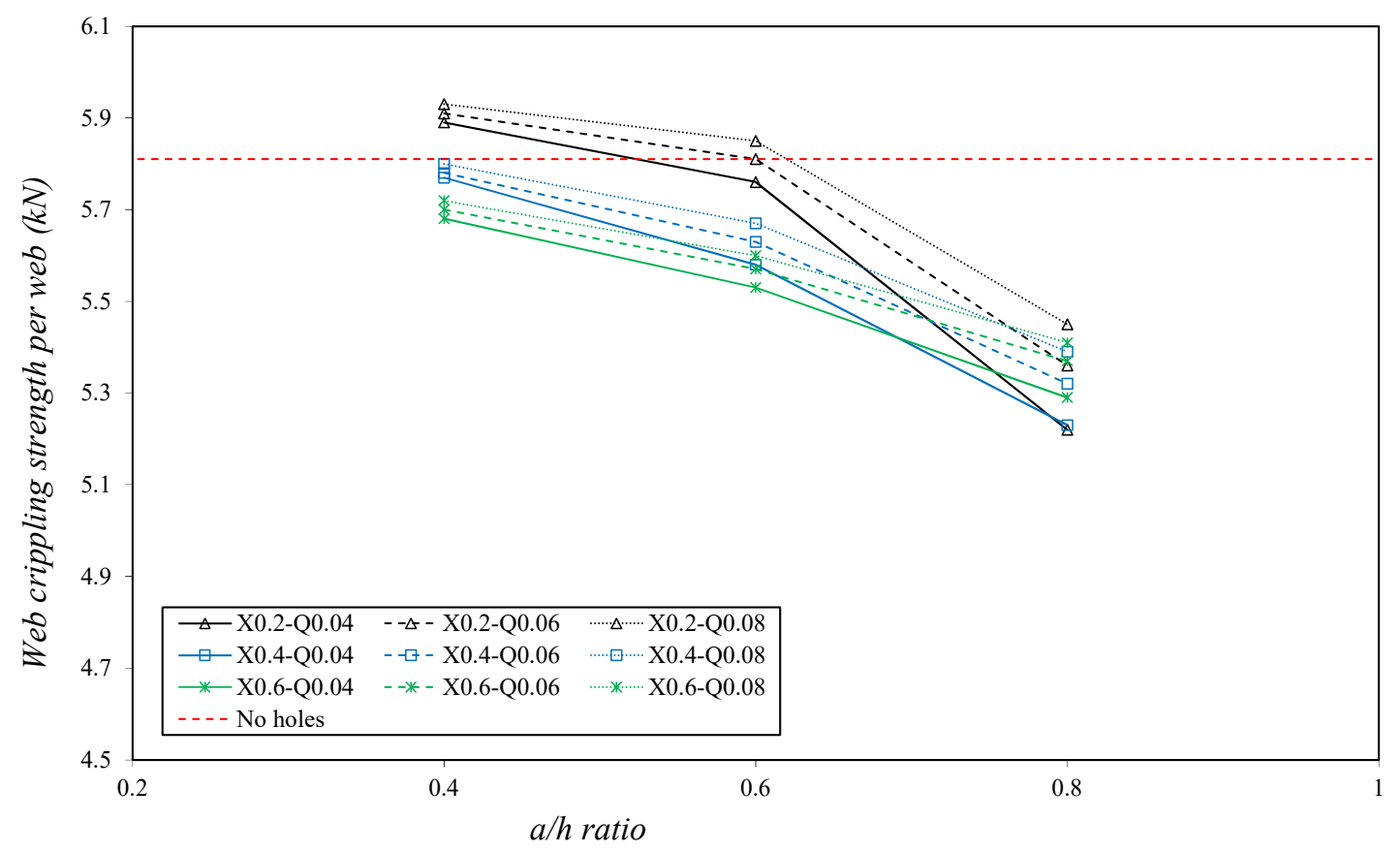

(b) EOF loading condition

Fig.12 Effect of $a / h$ ratio on web crippling strength 


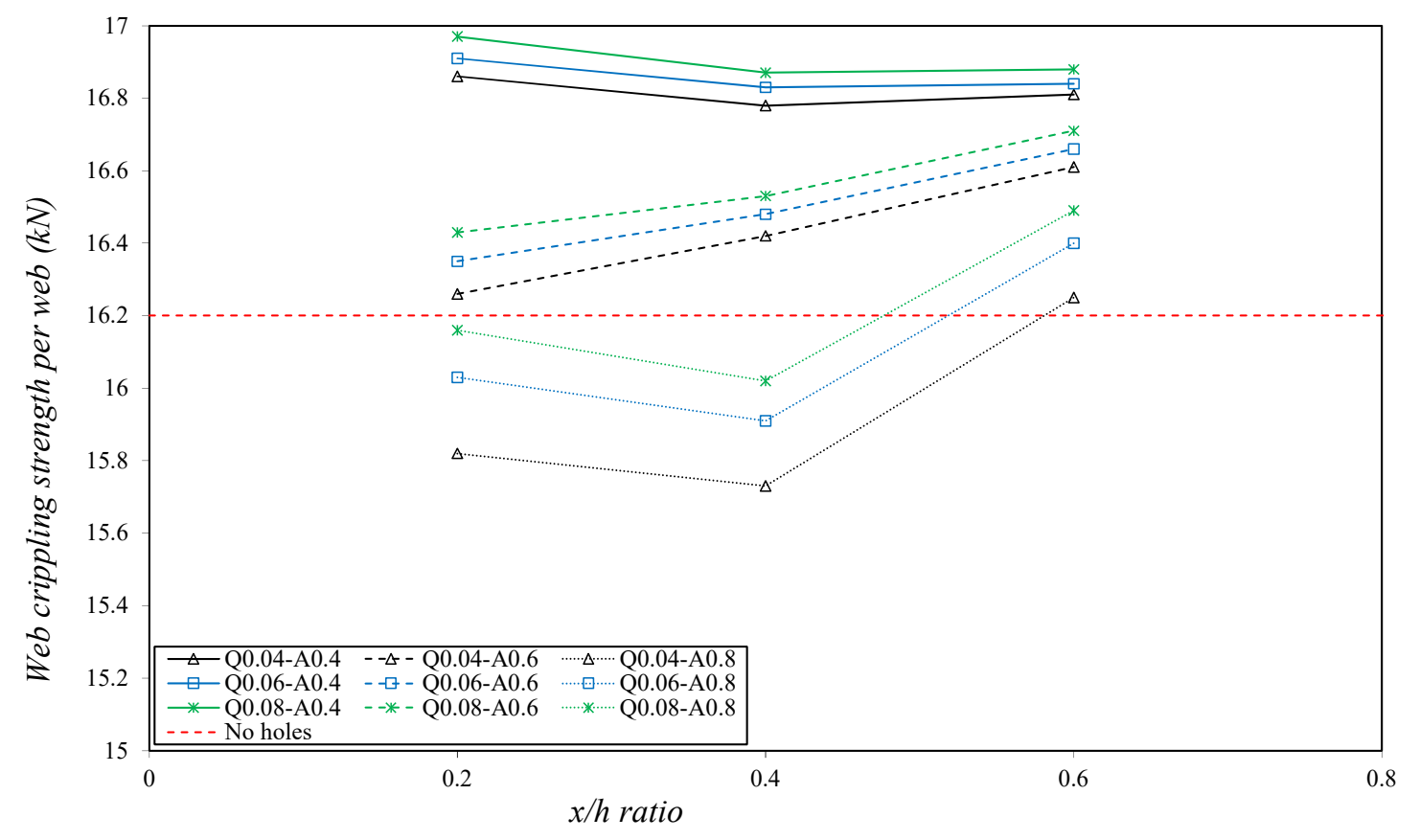

(a) IOF loading condition

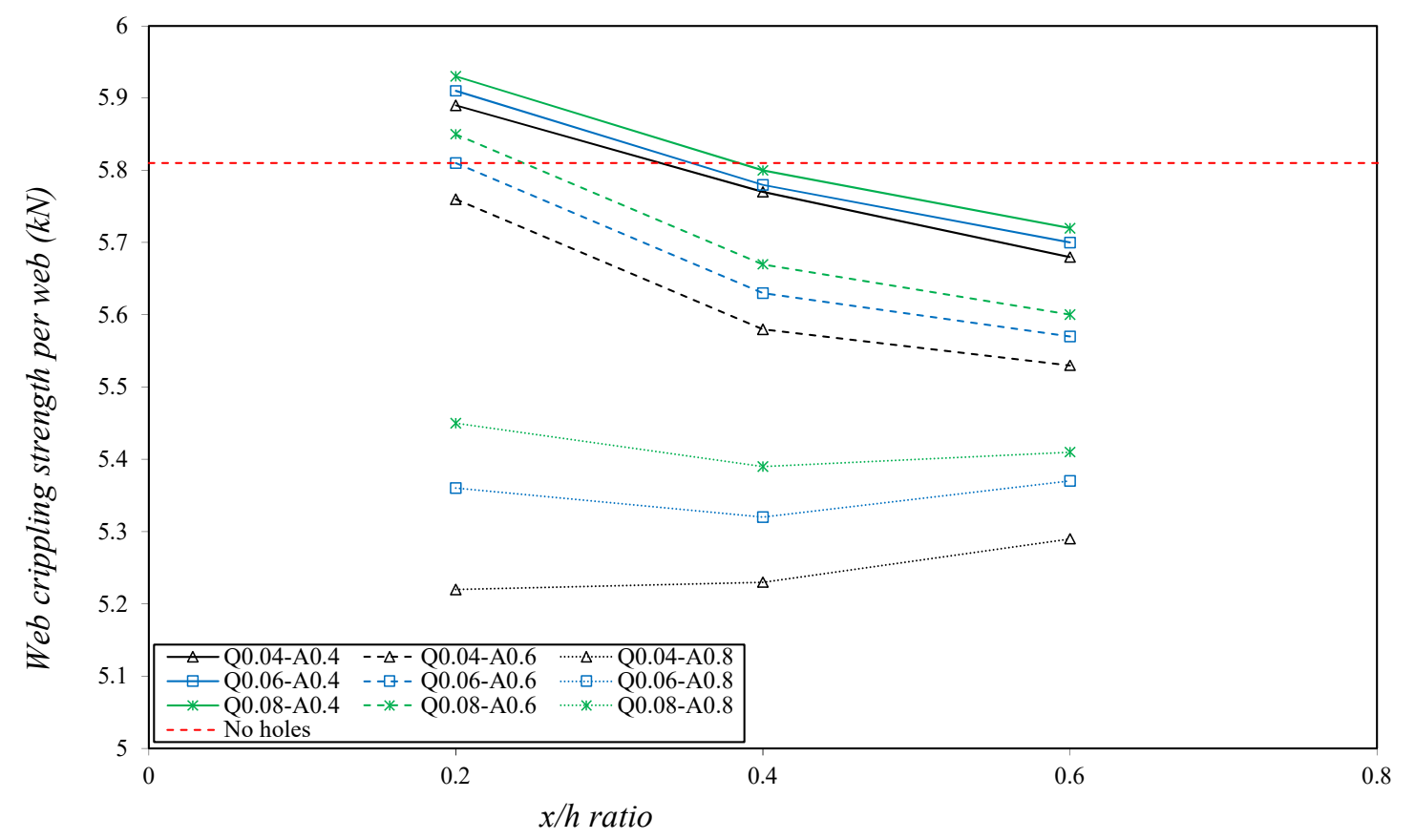

(b) EOF loading condition

Fig.13 Effect of $x / h$ ratio on web crippling strength 


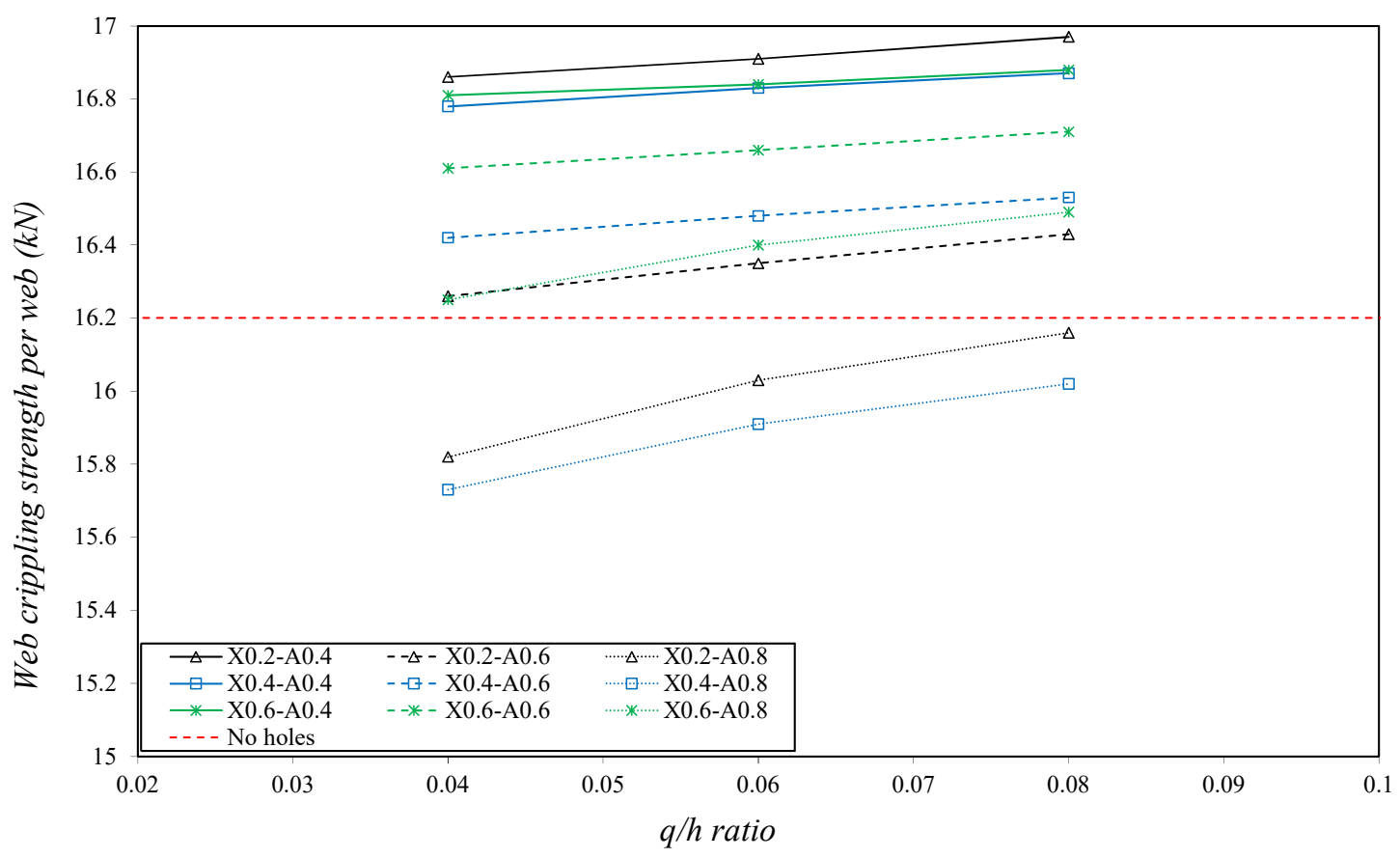

(a) IOF loading condition

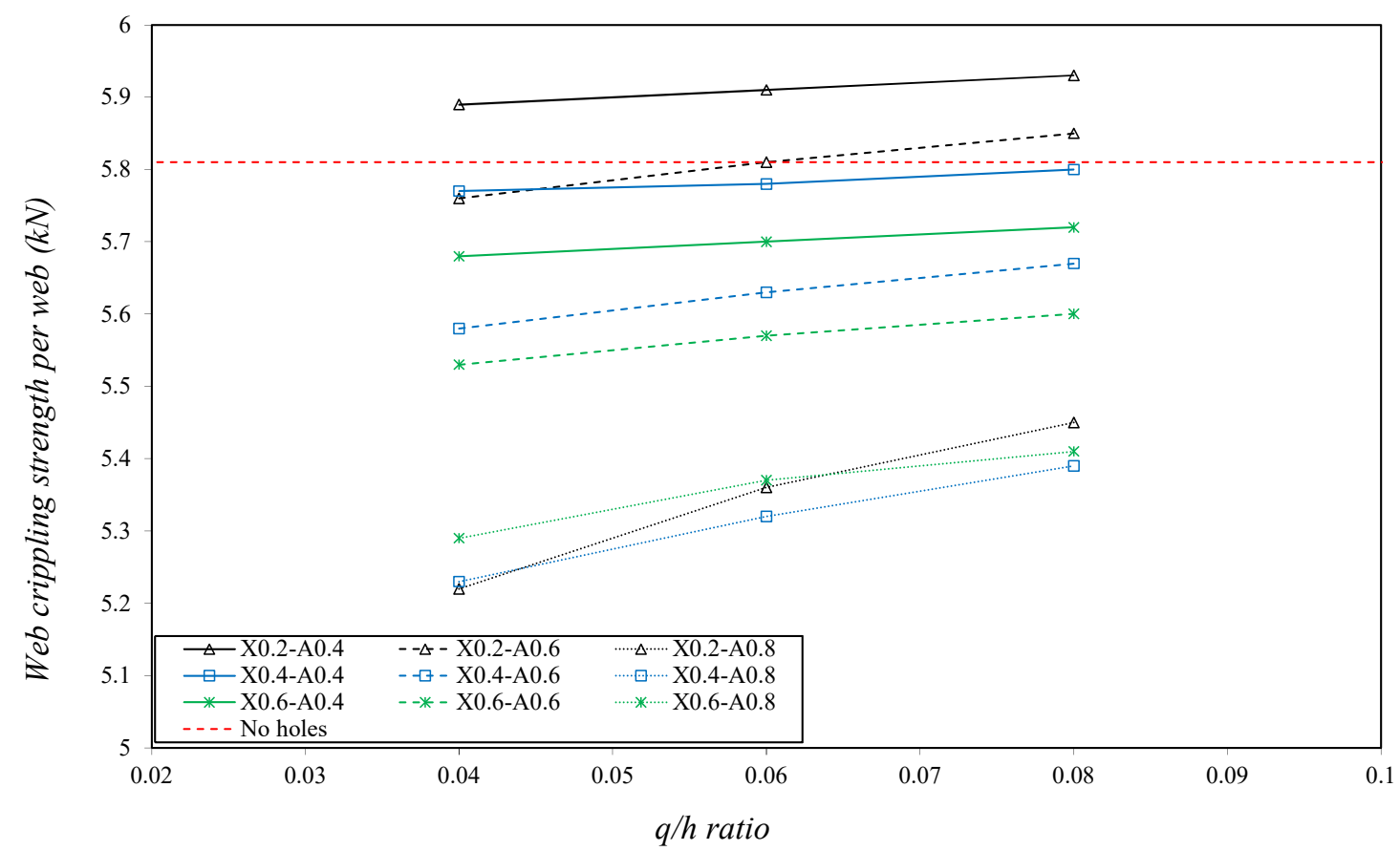

(b) EOF loading condition

Fig.14 Effect of $q / h$ ratio on web crippling strength 